Review

\title{
Exploring the Role of Stakeholder Dynamics in Residential Photovoltaic Adoption Decisions: A Synthesis of the Literature
}

\author{
Fabian Scheller ${ }^{1, * \mathbb{D}}$, Isabel Doser ${ }^{2}$, Daniel Sloot ${ }^{3}$, Russell McKenna ${ }^{4}$ and Thomas Bruckner ${ }^{2}$ \\ 1 Energy Systems Analysis, Division of Sustainability, Technical University of Denmark, \\ 2800 Kgs. Lyngby, Denmark \\ 2 Institute for Infrastructure and Resources Management, Leipzig University, 04109 Leipzig, Germany; \\ isabel_doser@yahoo.de (I.D.); bruckner@wifa.uni-leipzig.de (T.B.) \\ 3 Energy Economics, Institute for Industrial Production, Karlsruhe Institute of Technology, \\ 76131 Karlsruhe, Germany; daniel.sloot@kit.edu \\ 4 School of Engineering, University of Aberdeen, Aberdeen AB24 3FX, UK; russell.mckenna@abdn.ac.uk \\ * Correspondence: fjosc@dtu.dk
}

Received: 2 November 2020; Accepted: 24 November 2020 ; Published: 28 November 2020

\begin{abstract}
Despite the intensive research on residential photovoltaic adoption, there is a lack of understanding regarding the social dynamics that drive adoption decisions. Innovation diffusion is a social process, whereby communication structures and the relations between sender and receiver influence what information is perceived and how it is interpreted. This paper addresses this research gap by investigating stakeholder influences in household decision-making from a procedural perspective, so-called stakeholder dynamics. A literature review derives major influence dynamics which are then synthesized based on egocentric network maps for distinct process stages. The findings show a multitude of stakeholders that can be relevant in influencing photovoltaic adoption decisions of owner-occupied households. Household decision-makers are mainly influenced by stakeholders of their social network like family, neighbors, and friends as well as PV-related services like providers and civil society groups. The perceived closeness and likeability of a stakeholder indicate a higher level of influence because of greater trust involved. Furthermore, the findings indicate that social influence shifts gradually from many different stakeholders to a few core stakeholders later on in the decision-making process. These insights suggest that photovoltaic (PV) adoption may be more reliably predicted if a process perspective is taken into account that not only distinguishes between different stakeholders but considers their dynamic importance along the process stages. In addition, especially time- and location-bound factors affect the influence strength. This clearly shows the importance of local and targeted interventions to accelerate the uptake.
\end{abstract}

Keywords: low carbon technology adoption; social influence; decision-making process; residential photovoltaic; literature review

\section{Introduction}

\subsection{Social Influence in Residential Low-Carbon Technology Adoption Decisions}

The complexity of residential decision-making with respect to low-carbon technologies such as rooftop photovoltaic (PV) systems is vividly shown by the richness of theorized drivers and barriers that facilitate 
or hinder individual adoption decisions and the lack of a commonly agreed-upon decision process [1-4]. Typically, these studies aim at identifying antecedents of intention or behavior or drivers and barriers that facilitate or hinder adoption at the individual level (e.g., [5,6]). In particular, despite individual low-carbon technology adoption processes having been studied intensively and the acknowledgment of them having a complex, intrapersonal nature [1,3,7], there is a substantial gap regarding social influences (or in other words stakeholder influences) driving adoption decisions [8]. Back in 1943, the paramount importance of social influence for innovation adoption was already shown in Ryan and Gross' research ([9], as cited in [10]): "The hybrid corn study established diffusion as essentially a social process. A farmer typically adopted the innovation because of interpersonal communication with other farmers who already had adopted it [...]." Consequently, innovation diffusion is a social process in which "subjective evaluations of an innovation spread from earlier to later adopters rather than one of rational, economic-decision making" [10] alone. Communication structures, channels, and the relation between sender and receiver influence what information is perceived and how it is interpreted, thus they strongly affect individual decision making [1]. Yet, "social influence is often poorly theorized or simply absent from behavior models" [11], reducing their usefulness to explain and predict adoption behavior.

Despite the fact that there are varying approaches to decision-making, there seems to be a general consensus that even though "the decision to or not to adopt an innovation can be a one-time event, the route that leads to one's decision does not take place in a vacuum" [2]. Therefore, it requires a procedural perspective while considering external social factors which we capture as stakeholders in this paper. In many studies on low-carbon technology adoption, however, the procedural perspective is not explicitly addressed. Either the level of knowledge about the technology or the engagement in activities to prepare behavior are used to determine how close a decision-making unit is to adoption, or respondents are asked directly whether they intend to adopt the low carbon technology or not to determine intention. For example, in the case of residential solar energy systems, Labay and Kinnear [12] only distinguish between adopters, nonadopters who are aware and knowledgeable, and nonadopters who are unknowledgeable. MacPherson and Lange [13] distinguish between adopters, those that are seriously considering adoption, those that seriously considered but rejected, and the remainders. Wolske et al. [4] exclude PV adopters, those nonadopters who have contacted a solar company because "they might be at another stage of the decision process" and those who answered "don't know" in too many cases from their study. Ozaki [14] separates adopters, high-intention nonadopters, and the remainder. Individual scholars seem to agree that with increasing closeness to behavior or adoption, considerations become more specific, concrete, and context-dependent $[15,16]$. This is particularly true for high-involvement low carbon technologies such as solar PV: if a decision maker intends to adopt, he or she must seriously engage in planning to prepare adoption. Furthermore, it is in line with the explanations of two related and procedural theories, the diffusion of innovations [1], and the theory of planned behavior [17]. Only a few studies investigate the beginning of the decision process: in a study on PV adoption, Rai et al. [18] ask for spark events, and Wilson et al. [15] propose that household characteristics of domestic life primarily determine whether a decision-making unit begins to think about home refurbishments. In this regard, the most prominent attempt to describe the mental processes regarding innovation adoption is the diffusion of innovations theory by Rogers [1].

According to Geels et al. [19], previous research explaining decision-making behavior underappreciates the importance of social interactions with other actors, which we consider as stakeholders. Hereinafter, the term refers to any tangible actor, e.g., institution, organization, or group of individuals that in some way influence a household's low-carbon technology adoption process, may it be of direct or indirect nature. In this sense and in line with stakeholder theory, stakeholders represent an abstraction and aggregation of real-world actors according to different roles or functions they fulfill towards decision-makers. Consequently, more nebulous categories such as future generations or national interest are implicitly 
excluded. This raises the question of what constitutes the legitimate stake of "external" actors in residential low-carbon technology decision-making. From a general point of view, every human (and even future generations) has a legitimate stake in the adoption of low-carbon technologies. This is constituted through the positive implications that it entails and in which people are legitimately interested. The related emission reductions contribute, in the short term, positively to human health by e.g., improving air quality and in the long term to moderate negative impacts of climate change. By taking the residential decision-maker's point of view, it is argued in this paper that most if not all of the actors are seen as legitimate. Legitimacy is given for actors that are proactively involved by decision-makers themselves in the process, otherwise they would probably not have involved them in the first place. Less freely "choosable" actors (framework setters) like institutional and political actors are for instance legitimate through their stake of acting in public interest. Since Mitchell et al. [20] define an actor to be a stakeholder as soon as he or she possesses one or several of three attributes (power, urgency, or legitimacy), the application of the stakeholder term in this research can be justified. Moreover, the stakeholder term has been applied by Curtius [21] in the same context: "[Homeowners] are usually final decision makers of a PV investment, although influenced by other stakeholders."

It has also been criticized that many approaches to stakeholder analysis within the business management literature are static and fail to consider that the appearance of stakeholders and the perception of circumstances might change over time [22]. There are indeed several indications pointing at dynamic components regarding stakeholders. Kamal et al. [23] discuss the dynamic role of stakeholders regarding an adoption process of technology integration solutions in the public sector. They claim that each stage "is characterized by its own stakeholders, activities, and outcomes", point to stage-specific varying roles and interactions, as well as notice that "the intensity of different stakeholders' involvement in a particular phase may vary" [23]. Similarly, Postema [24] describes stakeholder dynamics related to IT-based innovation adoption processes in organizations. He mentions dynamics regarding changing viewpoints and wishes of stakeholders, a context- and time- dependent set and number of stakeholders, changing role involvements, and lastly changing nature of stakeholder salience which is defined as "the degree of influence of a stakeholder" [24]. In this sense, it can also be assumed that the social influence of stakeholders in the different decision-making stages of the low-carbon technology adoption process will be perceived differently. Stakeholder dynamics describe the changing degree of stakeholder influence along the various stages of the decision-making process.

Considering stakeholder dynamics helps to gain better insights in the stage-specific and / or contextand time-dependent influencing forces on the decision-maker. Furthermore, it seems valuable to investigate "the stakeholder salience dynamics during the process, in order to predict adoption outcomes more reliably" [24]. While the diffusion theory of Rogers [1] gives an initial insight, to date it is unclear to what extent the influence of different stakeholders is dynamic over the process of indiviudals' decision making regarding low-carbon technology adoption. The lack of knowledge regarding stakeholder dynamics and just an implicit consideration of the decision-making process is particularly disadvantageous when intervention strategies are designed. A procedural structuring and understanding of stated dynamics could be useful for policy makers, the business sector, or other actors aiming to accelerate low-carbon technology diffusion. Therefore, an intensified focus on stakeholder dynamics in the adoption process of household decision-makers is necessary. Considering that much influence in residential low-carbon technology adoption processes is hypothetically based on information gathered through different kinds of social influences, Berlo et al. [25] point to the fact that "an individual's acceptance of information and ideas is based in part on 'who said it'". This suggests that influence strength might depend on the perception of the attributes of the stakeholder that interact with the decision-maker. Put another way, a highly credible source might be more influential than a less credible source [26,27]. While Wolske et al. [4] found a positive correlation between perceived trust in a decision-maker's social network as well as the belief that the social 
network supports a PV adoption, Bale et al. [28] attribute a key role to local authorities because of their perceived spatial closeness. In this regard, a comprehensive evaluation of the relative influence seems to be only possible by underpinning the procedural stakeholder dynamics with the perceived stakeholder attributes [29].

\subsection{Research Objectives}

The research gap addressed is remedied by an exploration of relevant stakeholders and their influences on residential low carbon technology decision-making and in particular regarding PV technology. In other words, this paper seeks to understand how household decision-makers are "affected" by different stakeholders along the decision-making process, so-called stakeholder dynamics. For a systematic approach, the following research questions are used as a guideline:

- What types of stakeholders surround a residential decision-maker and how do they influence residential decision-makers in PV technology adoption decisions?

- What stakeholders have a decisive influence on residential PV adoption behavior at different stages of the decision process and which stakeholder attributes are important for the influence strengths?

To answer the research questions raised, this paper builds upon three theoretical approaches. Diffusion of innovations and similar adoption theories [1,15] provide a framework for modeling the residential low-carbon technology decision-making process. Stakeholder theory [22,30-32] contributes to the exploration of influential actors. Social network analysis [33-35] serves as a means to visualize stakeholder influences from the perspective of residential decision-makers. Bringing all fields together, stage-specific stakeholder influences on individuals at a household level can be visualized in egocentric network maps derived from literature. While a whole network analysis considers all relations (without focusing on a specific actor) within a defined network by taking "a bird's-eye view", egocentric network analysis captures only direct relations of alters surrounding a local actor termed ego [34,35]. The most basic level of such network is referred to as dyad which consists of a pair of actors, in this case the ego and an alter, as well as the tie between these two [33]. In this context, the ego network visualization in terms of PV decision-making in this paper shall depict all relevant dyadic ties (backed up by the proposed attributes) of a decision-maker at the household level to alters during the decision-making process. Consequently, ties represent (positive and negative) influences. The alters encompass the stakeholders identified. This network perspective combined with the procedural view is especially powerful to reveal the so far sidelined stakeholder dynamics.

Due to the expected strategic importance for the future energy system as well as the increasing awareness of the technology in society [5], residential PV systems make up the core of the analysis in this paper. Residential PV systems are locally available sustainable technologies. At the same time, they are only taking advantage of unused space on rooftops of existing buildings. The importance of facilitating residential adoption of the technology is underlined by the fact that according to [36], a "big part of solar PV's expansion will come from PV systems installed on homes, commercial buildings and industrial facilities". From a theoretical viewpoint, the research results provide a novel synthesis of the literature with special regards to the importance of stakeholder dynamics across different stages of households' decision making. From the practical viewpoint, the results of this research paper might aid in developing successful intervention strategies to accelerate the uptake of low-carbon technologies. 


\section{Research Design}

\subsection{Analytical Approach}

Our research builds on a literature review focusing on research outcomes and aims to integrate existing findings. The main emphasis is put on critically analyzing existing empirical results. We conducted an literature search on Web of Science, Scopus, and Google Scholar in the field of PV decision-making. Despite a certain focus on Germany, the literature review covers studies of several countries. In fact, the literature search has revealed that there are several studies on PV and also low-carbon technology decision-making in general, for instance in the United States and Sweden, that provide valuable insights for the research objective. In this context, articles with research from different countries and regarding several low-carbon technologies were considered in order to gain deeper insights. This allowed a more complete picture to be developed.

Varying combinations of different keywords related to stakeholder dynamics (influence, impact, stakeholders, actors, dynamics, peer effects), household decision making (residential, household, domestic, adoption, decision-making, behaviour, household transition), and the low-carbon technologies (solar photovoltaic system, photovoltaic, PV, solar energy, microgeneration, green electricity, green energy, energy retrofit) were used. Of special interest were peer-reviewed scientifically published papers dealing with variables of stakeholder dynamics regarding household adoption decisions with respect to PV technology. This is partly complemented through further research such as reports by research institutions or case studies.

The literature review has been integrated into our proposed analytical framework for this research depicted in Figure 1. Our research objectives could be matched through the four steps illustrated. In addition, the methods applied and interim results generated are demonstrated for each step.

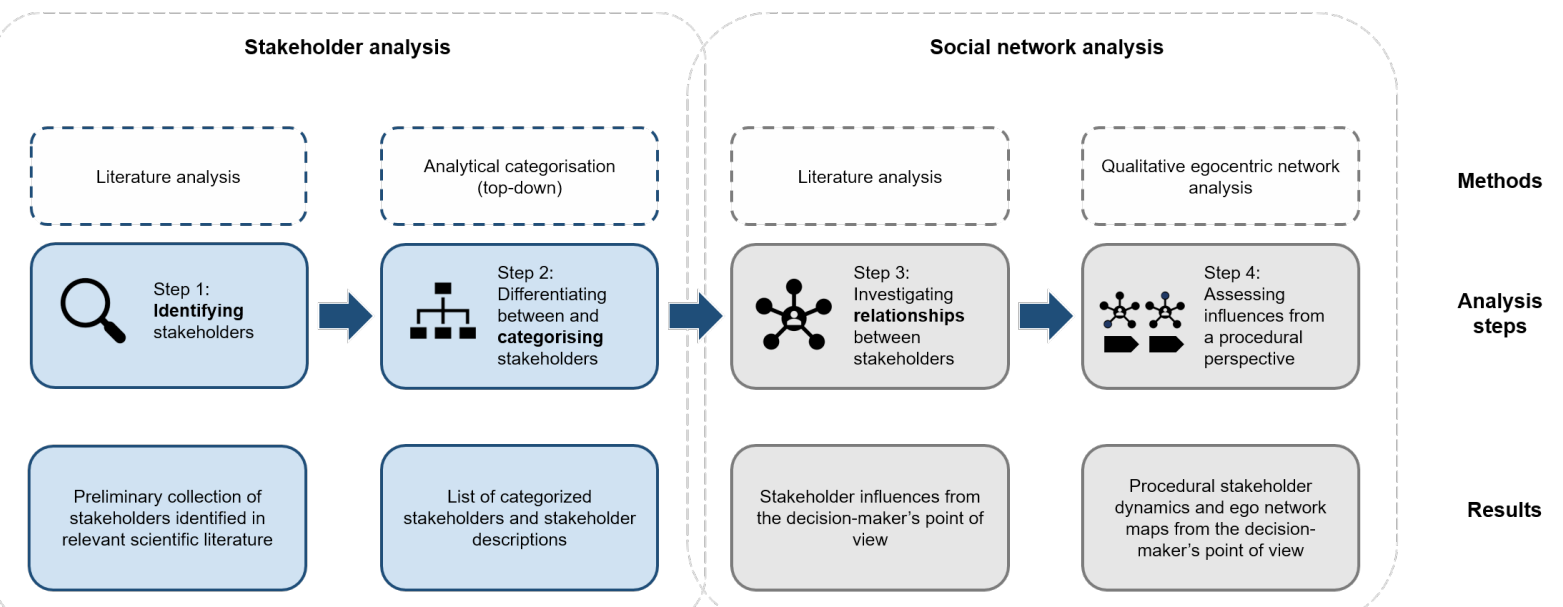

Figure 1. Analysis framework for stakeholder analysis and social network analysis to elaborate stakeholder dynamics in residential photovoltaic (PV) adoption (own illustration).

Step 1 and 2 (stakeholder analysis): Decision making as a highly social process and the energy system as a complex interplay of various parties both imply a variety of actors which need to be analyzed. A useful approach to identify and explore these actors is provided by stakeholder analysis. Reed et al. [22] see it as a means to answer the question "who's in and why?" and Varvasovszky and Brugha [37] define it as follows: "Stakeholder analysis is [...] a tool, or set of tools for generating knowledge about actors-individuals and organizations-so as to understand their behavior, intentions, interrelations, and interests; and for assessing the influence and resources they bring to bear on decision-making or implementation processes." 
To overcome typical biases emerging from "ad hoc" stakeholder analyses, we mostly follow the systematic procedure suggested by [22] which suggests the identification of stakeholders and their stakes in a first step, followed by the differentiation and categorization between stakeholders. In order to identify relevant stakeholders, the present body of literature was investigated resulting in an initial collection of actors. In a second step, this preliminary compilation was transformed into a list of relevant stakeholders categorized in a top-down manner. This was accomplished on the one hand by subsuming highly similar actors to a single stakeholder and on the other hand by structuring these stakeholders according to five fields which we formulated as superordinate categories.

Steps 3 and 4 (social network analysis): The evaluation of how influential different stakeholders are, is based on the point of view of household decision-makers and is addressed in this research by social network analysis. A network perspective has already been successfully implemented within a wide range of research and in particular, several times in the context of diffusion and adoption of innovations [1]. Egocentric network analysis and low-carbon technology decision-making operate on the same level: in both cases, the center of attention is a specific actor or a decision-making unit, respectively. Therefore, the egocentric view perfectly matches the research subject. In this regard, empirical literature results in terms of ego-stakeholder relationships are presented and compared as a third step. Subsequently as step four, the relative influences stakeholders have on household decision-makers have been assessed in two ways: (a) among stakeholders as well as (b) among decision stages. These results are visualized through three egocentric network maps which allow one to capture changing salience of different stakeholders throughout the process. In this context, the stakeholder categories are especially important to enable a clear and intuitive representation of the maps.

\subsection{Research Scope}

Since different underlying conceptual definitions and application contexts have implications on the purposes that stakeholder analysis and social network analysis should serve, the rationale behind relevant concepts are outlined in the following.

\subsubsection{Procedural Decision-Making Perspective}

An innovation-decision process or adoption process "examines the individual and the choices an individual makes to accept or reject a particular innovation" [2]. Rogers' [1] adoption model consists of five sequential stages in which a decision-making unit (house owner in this paper) evaluates an innovation and decides to either reject or incorporate it in ongoing practice. It is considered as a process of reducing uncertainty through accumulating different types of information induced through several communication channels throughout the process. A distinctive feature of innovation decision-making in comparison to other types of decision-making is the perceived newness and the resulting inherent uncertainty in the process. Wilson et al. [15] suggest three cross-sectional decision stages (thinking about, planning, finalizing) inspired by diffusion of innovations that are preceded by a stage at which the behavior is simply not considered and followed by implementation and use. However, their process is not related to the adoption of a low-carbon technology but to a behavior. These two example processes demonstrate that different perspectives are possible. Despite a lacking consensus on how to deal with adoption processes, several implications arise: first, there is a difference between simple awareness of the existence of an low-carbon technology and active decision making. Second, decision-makers accumulate knowledge in the decision process, and information becomes more object-specific over time. Third, forming a favorable or unfavorable attitude towards the low-carbon technology is a major component of decision-making. Fourth, in the case of a positive attitude, decision-making units might decide that they would like to adopt the low-carbon technology (intention) and begin to engage in concrete planning processes. Fifth, 
if planning has been successful, the behavior is executed thereafter. Although the process has been criticised for its linearity, largely excluding contextual configurations, external influences and not allowing for a reoccurring evaluation $[3,11,16]$, it allows a simple consideration of different stages.

Based on the implications and the two processes introduced, a framework for residential PV decision-making and adoption for this paper is depicted in Figure 2. In addition to the lightly altered designations of the process stages, it especially differs from the above discussed processes in the following issues: we explicitly distinguish between decision-making and adoption process. The decision-making consists of three stages (awareness, interest, and planning stage) whereas the adoption process reaches further and is extended by the implementation. This differentiation proves useful in relation to exploring stakeholder influences since the fourth stage occurs after the final decision to adopt PV has been made. Therefore, in the following, only the outlined triple-staged decision-making process is relevant. Furthermore, in order to allow a more precise definition of when a specific stage begins and ends, different moments of truth are included. Moment of truths are a concept used in marketing, describing moments where the inner attitude of customers with respect to a product changes. They represent points in time during the process which indicate and entail a behavioral change of the decision-maker. In this context, the awareness stage encompasses all influences, events, and interactions that are related to gaining first knowledge about residential PV. The interest stage is related to all influences, events, and interactions that occur when the decision-maker starts to develop an interest for residential PV and tries to accumulate more but rather general information about it. The subsequent planning stage includes all influences, events, and interactions when the decision-maker's interest has grown enough so that he has the intention to install a PV system. This stage is about the accumulation of more detailed and concrete information. Finally, the decision-maker enters the implementation stage when a contract has been signed and they successfully turn into an adopter and change behavior.

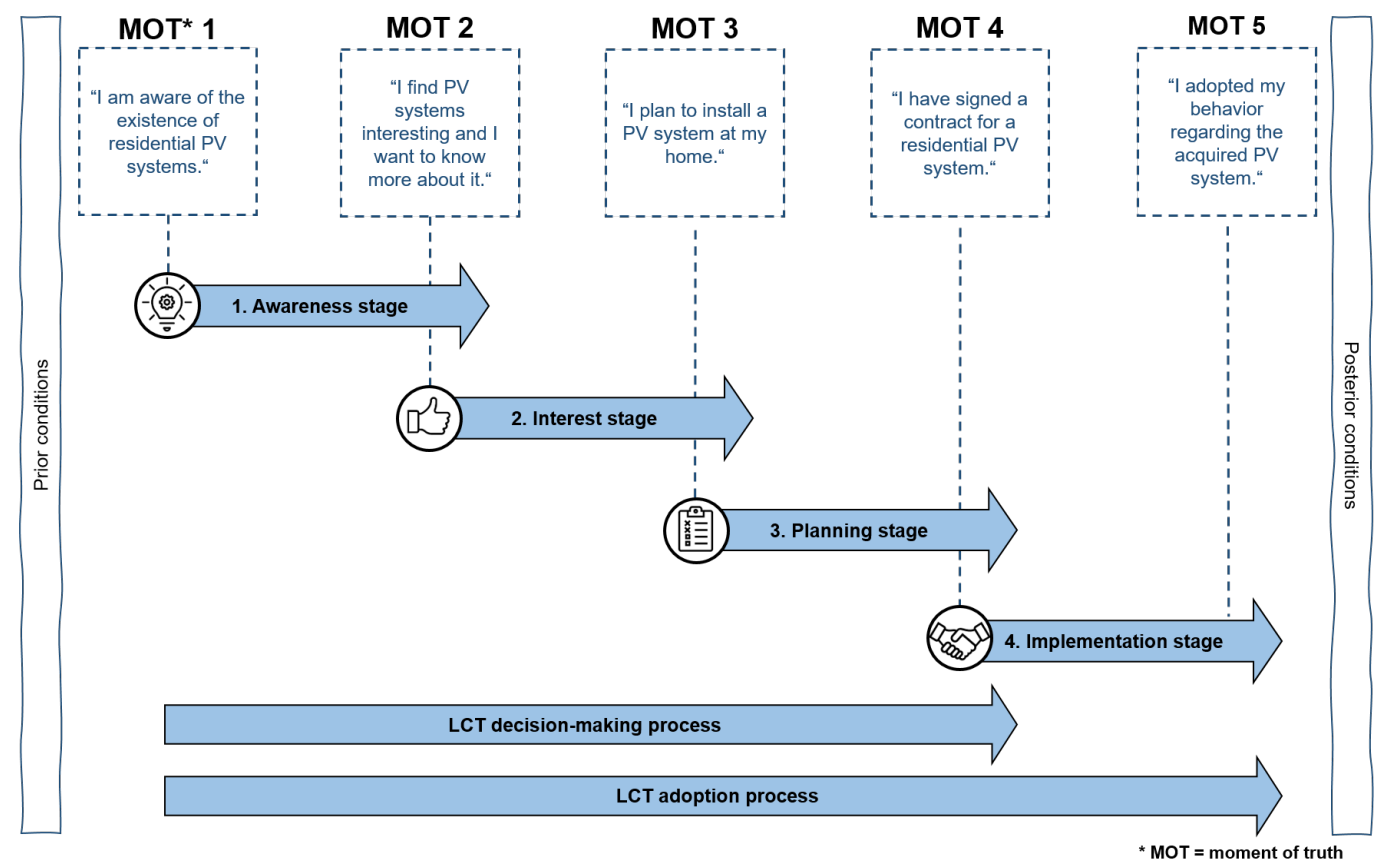

Figure 2. Process stages of residential low-carbon technology decision-making with particular attention to the behavioral transitions (MOT = moment of truth). According to the objective of this paper, the three stages of the decision-making process (awareness, interest, planning) are in focus (own illustration). 


\subsubsection{Stakeholder Landscape for Residential PV Decision-Making}

The literature review revealed that there has been little research regarding the establishment of a stakeholder landscape that influences households' low-carbon technology adoption processes. If several stakeholders are the subject of a study, they often lack a description on how the stakeholders were determined (e.g., [38]). Another important point is that the actors who are termed stakeholders in this paper are not always identically referred to in previous research. Instead, they also emerge as "information sources" (e.g., [18]) and "information channels" (e.g., [39]). Further research investigates for instance only single stakeholders and their influence on decision-makers (e.g., [40] outlined the influence of low carbon retrofit advisors and installers).

An overview of relevant stakeholders in the adoption of mature energy-saving technologies in new residential buildings is given by Berardi [41]. In addition to various stakeholders from the construction sector (e.g., architects, project managers, general contractors), he mentions local, regional and national government, neighbours, and NGOs complemented by consultant engineers. Curtius [38] identifies important stakeholders within his conceptual dissertation framework which are involved to a different extent in the PV adoption process. He brings up neighbors, policy makers, manufacturers, installers/PV salespeople, architects, and a cluster including real estate developers, strategic investors (like energy utilities), and institutional investors (like banks and investment funds). Rai et al. [18] also contribute to some extent, as they listed potential information sources in PV adoption decision-making as follows: coworkers, members of online forum(s), online resources, roofing contractors, solar installers, neighbors, local nonprofit groups, acquaintances, family, and local utility. In the same context, Alipour et al. [39] highlight the importance of five stakeholder groups occurring as information channels: government, business/NGO, supplier, peers, and media. Further research complements the list with craftsmen [42], commercial energy advisors [40], publicly funded energy consultants [43], and solar initiatives [44]. Additionally, scientists might play a role.

Thereby, all seemingly different stakeholders are brought up at least once. This initial collection of stakeholders outlines two things: first, none of the research mentions nor fully describes all potential stakeholders and second, albeit they seem numerous, some stakeholders refer to the same actors but are differently denominated (e.g., government and policy makers) or are actors of a similar kind (e.g., peers and acquaintances, neighbors, etc.). This makes it even more necessary to develop stakeholder categories and to provide precise definitions. Table 1 presents the edited list of stakeholders subdivided into the five stakeholder categories social network, energy system and PV-related services, government/authorities and other institutions, media, and others. A description of each stakeholder or stakeholder cluster, if several single actors found in literature have been subsumed to one stakeholder respectively, is also provided. Furthermore, an overview of the relevant studies in dependence of the stakeholders is outlined. 
Table 1. Stakeholder mapping and classification based on their role in the PV adoption processes (own compilation).

\begin{tabular}{|c|c|c|}
\hline Stakeholder & Description & Reference \\
\hline \multicolumn{3}{|l|}{ Category: Social network } \\
\hline Partner & Spouse or life partner with whom decision is made & {$[45]$} \\
\hline Family & Family members and relatives & {$[4,18]$} \\
\hline Friends & Persons in decision-maker's (immediate) social circle & {$[4,8,18,46]$} \\
\hline Acquaintances/coworkers & Persons in decision-maker's wider social circle & [18] \\
\hline Neighbours & Persons living in decision-maker's neighborhood & {$[8,18,38,41,46-51]$} \\
\hline Other private persons & $\begin{array}{l}\text { Private persons outside decision-maker's social circle with an interest } \\
\text { in photovoltaic (e.g., fair visitors, forum contributors) or other previous } \\
\text { adopters }\end{array}$ & {$[18]$} \\
\hline \multicolumn{3}{|c|}{ Category: Energy system and PV-related services } \\
\hline Local utilities & Energy providers operating locally (e.g., city or communal providers) & {$[18,38,46,52,53]$} \\
\hline $\begin{array}{l}\text { State/national-level } \\
\text { utilities }\end{array}$ & Energy providers operating in many locations (e.g., E.On, RWE) & {$[18,52,53]$} \\
\hline PV manufacturers & $\begin{array}{l}\text { Photovoltaic producers (if a PV manufacturer also sells PV systems to } \\
\text { customers at the household level, it is considered as PV provider) }\end{array}$ & {$[38,46]$} \\
\hline PV providers & $\begin{array}{l}\text { Private companies that sell and install PV systems to household } \\
\text { decision-makers, often providing additional services such as consulting } \\
\text { and maintenance }\end{array}$ & {$[5,18,38-40,42,44,54-56]$} \\
\hline Energy advisors & $\begin{array}{l}\text { Experts in the private sector who offer information or advice regarding } \\
\text { energy issues for a fee }\end{array}$ & {$[18,40,41,57]$} \\
\hline $\begin{array}{l}\text { Nonprofit } \\
\text { organizations/associations }\end{array}$ & $\begin{array}{l}\text { Independent (public) organizations that offer information or advice } \\
\text { regarding energy issues (e.g., consumer organizations, energy agencies, } \\
\text { non-profit organizations) mostly free of charge }\end{array}$ & {$[18,39,41]$} \\
\hline Solar initiatives & $\begin{array}{l}\text { Formal or informal organizations stemming from civil society engaged in } \\
\text { the support of renewable energies and PV in particular }\end{array}$ & {$[44,58,59]$} \\
\hline \multicolumn{3}{|c|}{ Category: Government/authorities and other institutions } \\
\hline $\begin{array}{l}\text { Funding bodies/financial } \\
\text { institutions }\end{array}$ & $\begin{array}{l}\text { Financial institutions that play a role in financing photovoltaic } \\
\text { investments (e.g., banks, development banks, credit unions) }\end{array}$ & {$[38,42,44,58]$} \\
\hline Local governments & $\begin{array}{l}\text { Communal policy makers, government offices and organizations (e.g., } \\
\text { city hall, communal building authority) }\end{array}$ & {$[28,41,60-62]$} \\
\hline $\begin{array}{l}\text { State/national } \\
\text { governments }\end{array}$ & Policy makers and authorities at state and national level & {$[41,51,61-64]$} \\
\hline \multicolumn{3}{|l|}{ Category: Others } \\
\hline Scientists & $\begin{array}{l}\text { Researchers engaged in research on energy-related issues (e.g., from } \\
\text { research institutions or universities) }\end{array}$ & [58] \\
\hline Building professionals & $\begin{array}{l}\text { Professionals in the construction sector including private companies that } \\
\text { plan and undertake building construction and renovation work (e.g., } \\
\text { builders, architects) }\end{array}$ & {$[38,41,65,66]$} \\
\hline \multicolumn{3}{|c|}{ Category: Media channels* } \\
\hline Advertisement & $\begin{array}{l}\text { All kinds of off- and online advertisement (e.g., leaflets, banners) united } \\
\text { by promotional intention }\end{array}$ & [18] \\
\hline Online sources & Unspecified online sources (e.g., "googling around") & {$[5,18,67]$} \\
\hline Social media & Online communities (e.g., Facebook, Instagram, Twitter, YouTube) & [68] \\
\hline Mass media & Off- and online media coverage in newspaper, magazines and television & {$[1,18]$} \\
\hline Trade/ scientific journals & Energy- or technology-related (scientific) journals (e.g., Photon) & [18] \\
\hline
\end{tabular}

* Media plays a particular role since the channels are not interpreted as proper stakeholders. The channels are used by all different kinds of stakeholders. In this context, the tangible stakeholders "behind" seem to be rapporteurs who are responsible for media coverage but they cannot be treated like the other mentioned actors. Instead of directly integrating rapporteurs as actors into the decision-making landscape, the channels through which information is conveyed are taken into account. Usually rapporteurs do not act for their own sake but on behalf of certain stakeholders to get information across society as target group. In this regard, it is not always visible which stakeholder really is behind media coverage. 


\subsubsection{Stakeholder Influences, Attributes, and Dynamics}

The stakeholder approach builds on social influence approaches [30,69], however, when it comes to defining influence in the first place, the stakeholder literature does not provide theoretical groundwork [22]. Drawing on social psychology literature, influence is defined by Nelson and Quick as the "process of affecting the thoughts, behavior, and feelings of another" ([70], as cited in [22]), and social influence is seen by French and Raven as "a change in the belief, attitude, or behaviour of a person [...], which results from the action of another person" ([71], as cited in [72]). More importantly, it is about relative influence strengths among different stakeholders which requires indicators that might substantiate statements about relatively more or less influence of a particular stakeholder.

Considering that much influence in residential low-carbon technology adoption processes is hypothetically based on information gathered through different kinds of communication, Berlo et al. [25] point to the fact that "an individual's acceptance of information and ideas is based in part on 'who said it'". This fact should not only be interpreted regarding verbal communication but should be extended to all kinds of influences regarding communication and interaction with decision-makers. This suggests that influence strength or in other words communication effectiveness might not only depend on the individual person that interacts with the decision-maker but might also differ according to the stakeholder category this person belongs to. In this context, source credibility theory can provide valuable insights as previous research emphasizes that a source's credibility impacts the stakeholder's ability to influence others [29]. Put another way, a highly credible source is more influential than a less credible source. Several authors have operationalized credibility in different ways [73]. Individual credibility dimensions (hereinafter referred to as (stakeholder) attributes) might serve as a basis in this paper to underpin the evaluation of relative influence in terms of PV adoption.

Empirical evidence indicates that a message is perceived as most persuasive when the communicator is regarded as both an expert and trustworthy [27], suggesting a dependency between the number of attributes a source possesses and the level of effective communication. In line with McGinnies and Ward [27], the findings of Lui and Standing [74], however, suggest that trustworthiness is more important for effective communication than expertness. Therefore, the attribute likeability is considered in addition to the most frequently mentioned dimensions expertness and trustworthiness. Expertness shall refer to the degree a stakeholder "is perceived to have the adequate knowledge, experience or skills" [26] with respect to PV. Trustworthiness shall express "the degree of confidence in, and level of acceptance of, the [stakeholder] and the message" [73] as well as refer to a stakeholder's "honesty, integrity and believability" [26]. Likeability is linked to the source's personality [75] and shall refer to "the establishment of affective intimacy between source and its receiver" [74].

An intertwined attribute relates to power; credibility cannot only constitute perceived power [29] but it is simultaneously an autonomous source of influence. Moreover, (social) power is defined as the "potential for [social] influence, the ability of the agent or power figure to bring about [..] change, using resources available to him or her" [72]. French and Raven introduced in Steiner and Fishbein [76] five bases of power of which the legitimate power base corresponds to how the power attribute shall be understood hereinafter: power shall be interpreted as the decision-maker's perception that the stakeholder has the legitimate right to influence the decision-maker and that they must comply; power might also be seen as an "imposed" influence attribute in such way that the decision-maker might be for instance restricted or controlled in its scope of actions. Last but not least, geographic proximity has been identified as an important factor regarding low-carbon technology adoption. Early research on innovation diffusion suggests that spatial distance conditions the likelihood of social influence [77]; this means that the higher geographic proximity, the higher the likelihood of influence (e.g., communication). Moreover, Meyners et al. [78] found that 
geographic proximity not only increases the likelihood but also actual influence strength. Therefore, an additional attribute termed closeness is considered referring to spatial distance.

\section{Literature Results}

\subsection{Social Network}

The literature results of the first stakeholder category are presented in the following.

\subsubsection{Neighbors}

Neighbors and their influence on decision-makers have been the subject of investigation within multiple studies (e.g., [18,47-51]). The neighbor's influence is often referred to as a peer effect resulting from social interaction [47]. Thereby, peers are considered as "proximate adopters in preceding periods" [51].

Bollinger and Gillingham [47], Graziano and Gillingham [50], and Rode and Müller [51] provide strong evidence for a cause-and-effect relationship between proximate prior installations and a household's decision to adopt in the U.S. and Germany. Palm [8] criticizes that "such 'neighbourhood peer effects' have been predominantly studied using quantitative approaches, while their underlying mechanisms have remained poorly understood." According to Bollinger and Gillingham [47], peer effects develop as a consequence of visibility of the panels (passive peer effects [48]) and word-of-mouth (active peer effects [48]). The passive peer effect is assumed to represent a substantial part of the entire peer effect $[47,48,51]$. In contrast to this, the qualitative research of Palm [8] reveals that decision-makers assessed active peer effects to be more important than passive ones. Rai and Robinson [48] assume that active peer effects may arise from passive peer effects, whereas Palm [8] could not find evidence that seeing PV systems fostered contacts with previous adopters. Communication between decision-makers and adopters in their neighborhood took place more often with persons they rated as a "friend" or a "relative" than someone that just lives in the close environment [8]. This strengthens the findings of Palm [46], which indicate that proximate peers that are primarily seen as neighbors had rarely been recognized as influential in comparison to other proximate acquaintances. These results may be different due to cultural and societal factors as "Swedes might be less prone to talk to their neighbours than are people in the U.S. or Germany" [8]. Nevertheless, it can be assumed that likeability and a likely related trustworthiness are relevant for active peer effects. Rode and Müller [51] state that visibility drives peer effects in both rural and nonrural areas while peer-to-peer communication is only of major importance for rural areas since neighbors are more closely related. This could mean that rural peer effects more likely arise from both closeness and likeability, whereas closeness more likely drives peer effects in urban areas. Furthermore, Rode and Müller [51] interpret the PV systems nearby as "a large diverse pool of information which reduces uncertainty". Rai and Robinson [48] and Wolske et al. [4] have a similar understanding and interpret the influence of a decision-maker's neighbor as a means of providing valuable and trustworthy information. Thereby, peer effects even shorten the duration of the decision-making process [48,79].

Rai et al. [18] find that seeing a neighbor install a system or a conversation with a neighbor are common spark events; these two spark events combined were mentioned by households nearly as often as direct marketing, retirement planning, and increasing electricity rates [18]. Palm [8] speculates that "if [the] awareness had been lower at the moment of seeing local PV, the sighting could perhaps have been important in raising the awareness."

Different studies (e.g., $[47,50,51,80,81]$ ) agree on decreasing peer effects with distance and therefore strongest peer effects on a very small scale. However, according to Müller and Rode [80] the spatial peer effect appears to fade after $1.2 \mathrm{~km}$, whereas Graziano and Gillingham's [50] results still suggest highly statistically significant effects up to a 4 mile $(6.4 \mathrm{~km})$ range. They explain this difference with different 
radius of movements to pursue social interactions [50]. These spatial-dependent limitations of peer effects provide strong evidence that closeness has a major impact.

There are also differences in terms of time. Firstly, Rode and Müller [51] find evidence for a higher peer effect at the early stages of PV diffusion, implying a decreasing peer effect over time as the PV diffusion path evolves. They explain this fact by a higher uncertainty at early stages. The second implication is related to the time span since a PV system has been installed in the neighborhood and how a decision-maker is influenced by it $[50,51]$. More precisely, "previous installations have less of an effect on increasing the likelihood of new installations as time goes on" [50]. They reason the time-dependent decrease by the fact that decision-makers are likely to get used to the existence.

\subsubsection{Partner, Family, Friends, as Well as Coworkers and Acquaintances}

Even though peer effects are often localized, they can also occur through nonlocal peers referring to other persons in a decision-maker's social network besides neighbors. The importance of a decision-maker's social network has also been pointed out by various studies in terms of low-carbon technology adoption (e.g., $[4,18])$. One stakeholder of the social network that is often not mentioned explicitly is a decision-maker's partner or spouse. Since the decision about cost-intensive acquisitions in households is most commonly made collectively [45], both partners are involved in decision making and can be seen as joint decision-makers.

The results of Palm [8] suggest that "established social connections [are] more important than geographical proximity", as most active peer effects resulted from existing relationships such as friends, colleagues, or relatives. "Local peers" have even been rated as influential as installation companies by decision-makers, whereas local peers only being categorized as neighbors were rarely perceived as influential in comparison to local persons to whom the respondents had a personal relationship [46]. In this regard, the results of Rai et al. [18] are somewhat opposing while only giving limited insight: less than a fifth of the respondents mentioned the spark event "conversation with friend/family/work" and the median response regarding the importance of information from family, acquaintances, and coworkers was rather low [18]. Similar are the results regarding members of online forums as the median importance of information was also "not important at all". Friends influenced survey respondents (in this sense PV adopters) most when it comes to referral marketing; but it is added that solar companies probably incentivized these referrals [18]. However, decision-makers who experienced neighborhood peer effects at early stages of the adoption process value information through their social network more than decision-makers without neighborhood-related peer effects [18].

According to Palm [8], independent of being a local or nonlocal peer, the contact was most commonly proactively established by the decision-maker in order to get information, or the previous adopter and the decision-maker met for another purpose but the topic came up in the course of conversation. Furthermore, it was revealed that the decision-makers (who already had at least basic knowledge of PV systems) perceived the information as "a confirmation from a trustworthy source (i.e., a person that the participants knew and who was in a similar situation as themselves), and that the technology worked as intended and without hassle" [8]. The information was perceived as useful even though it was rather basic information and gave the decision-makers "a general sense of comfort regarding the investment" [8]. Wolske et al. [4] found a positive correlation between perceived trust in a decision-maker's social network as well as the belief that the social network supports a PV adoption and the interest in learning about PV systems of their peers.

To sum up, the social network, in particular in terms of previous adopters and thereto related local and nonlocal peer effects emerging from different stakeholders classified as part of the social network, represents an important factor throughout the decision-making process and was rated, according to 
Palm [8], nearly as important at later stages than at earlier stages of the process. This means that the overall social network only slightly loses importance as the decision-maker moves forward in the decision-making process. It is assumed that neighbors to whom decision-makers already had some sort of relationship are the most influential stakeholders in the social network as a result of closeness and likability; if not, neighbors are still highly influential through passive peer effects. Nonlocal stakeholders more or less "imperatively" perceived as trustworthy like friends/acquaintances and family are also estimated to be highly influential (likability) while in comparison coworkers are rated less influential. This is based on two considerations: on the one hand, trustworthiness cannot be attributed based on the relationship which weakens the influence strength; on the other hand, the earlier demonstrated empirical evidence also points to a slightly weaker influence strength in comparison to neighbors, friends/acquaintances, and family. The stakeholder group other persons is rated as not very important during the whole process because (a) forum contributors were rated by the majority to be not important, (b) other unknown previous adopters that shape the physical environment in which decision-makers move (e.g., farmers) most likely are only influential through passive peer effects and (c) additionally, the likability of these influences is limited since there is no personal relationship nor spatial closeness which would foster any contact or kind of influence.

\subsection{Energy System and PV-Related Services}

The literature results of the second stakeholder category are presented in the following.

\subsubsection{PV Providers}

The important role of low-carbon technology providers and installers is addressed by several researchers [18,40,44,55]. Fabrizio and Hawn [54] found that the number of solar power installations increased more in cities where the presence of local installers was higher. Owen et al. [40] describe installers of different domestic energy technology retrofits as "largely overlooked" change agents and Karakaya et al. [55] describe them as "vital in the adopters' decision process". Installers put the technologies in place and often, they occupy a double role as they also act as advisors [40]. In the PV sector, this role is often occupied by solar companies whose activities focus on "the promotion, consulting, conceptual designing, assembling and installation" [55].

Wolske et al. [4] found that trust in installers conditions the likelihood of decision-makers to establish contact. The extent to which decision-makers make use of advisory services of installers can be determined by the availability of previous adopters in their social network: in cases of missing previous adopters in the social network, the installer turns into a critical factor [40]. The study of Rai et al. [18] strengthens the importance of this stakeholder as interactions with solar companies were perceived as a very competent information source later on in the decision making. Furthermore, direct marketing by solar companies represented "the most popular spark event" [18]. Wolske et al. [4] found no significant influence of PV marketing at later stages which is in line with the theory of Rogers in which a decreasing influence of mass media communication is described while direct communication gains in importance [1].

However, direct marketing at early stages might constitute the attributed importance of solar companies at later stages as the findings of Rai et al. [18] suggest. Among those respondents who were exposed to direct mail marketing, the social network lost importance as an information source and installers emerged as primary sources of information. The installer-initiated spark event direct marketing allows solar companies "successfully shepherding these hard-won customers through the decision-making process" [18]. The findings of Palm and Eriksson [5] are opposing: several households in Sweden assessed information from suppliers as too technical and not neutral, leading to distrust in information from the solar companies and even to nonadoption. Karakaya et al. [55] assess "a high level of communication" between solar company and adopter as important for reducing perceived complexity as 
well as encouraging the adoption. They also identified a supplementary influence of local solar companies through peer effects [55]. Thereby, the likelihood for resultant active peer effects might be higher than in the case of neighbors due to the business nature of solar companies. These peer effects add to the salience of providers in the PV industry at very early stages of the process provided that the decision-maker is located nearby. It can be concluded that PV providers are influential at the awareness stage through marketing and, if applicable, passive peer effects and at later stages even more influential through direct communication as an important source of information and lastly the installation in the event of a positive adoption decision.

In this context, less specialized stakeholders like usual craftsmen can also be involved in the decision-making process. Zedan and Miller [56] ascribe them the lowest influence because they mainly occur as executors. Huber [42] brings up that there can be shortcomings in quality regarding energy efficiency measures or relatively new low-carbon technologies. Craftsmen were described as not up to date since they "often still sell products, which they have offered in the past 20 years, and miss to continuously train themselves" [42]. Furthermore, today there is a huge number of more specialized stakeholders like solar companies offering the whole range of PV-related services, so usual craftsmen might be much less important than several years ago in the solar industry. The survey of Rai et al. [18] seems to support this assumption: the median response for roofing contractors as important source of information was "not important at all" while solar installers were considered to be very important. Since craftsmen fulfill the same role as installers, they are also ranked among the more general term PV provider albeit the service portfolio is much narrower. The scarcity of craftsmen and eventual lacking knowledge and skills weaken to a small extent the positive influence of PV providers on decision-makers.

\subsubsection{PV Manufacturers}

The production of PV technology is roughly carried out by two actors. Specialized manufacturers produce solar cells which are then delivered to system suppliers. They finalize the product by assembling all components for the turnkey PV systems (modules, cables, and inverters) [44]. Both stages in the production value chain are accounted to the stakeholder PV manufacturer in this paper. Today, the system suppliers mostly function as wholesalers and sell the product to PV providers which serve as middle actors between PV manufacturers and private households [44]. This can be partly explained by the fact that a substantial part of low-carbon technologies, especially referring to PV systems, is nowadays produced outside of Europe and the full-service providers need to bridge the physical distance.

Another reason can be found within the maturing of the German PV market [44]: In an early market phase, the system suppliers had to serve the whole value chain (installation of residential PV systems included) because there was not yet an established distribution network. Along with market maturation, PV providers entered the market. This means that today, the manufacturer only influences the decision-maker indirectly in terms of product-specific attributes like aesthetics and costs [38] but is most commonly not actively involved in the decision-making process. Nonetheless, as described by Palm [46] for residential systems, it can sometimes also be a local manufacturer that offers installation and additional services such as seminars and courses in the municipality or region. In this particular case, the PV manufacturer would however be seen as PV provider instead of PV manufacturer. This suggests that PV manufacturers most likely play a subordinate role throughout the decision-making process and local PV providers serving as middle actors like solar companies are relatively more important in the adoption process. 


\subsubsection{Energy Advisors and Nonprofit Organizations}

Similar to PV providers, energy consultants are also referred to as overlooked change agents [40]. This is supported by the results of Michelsen and Madlener [57] who found that German homeowners are generally susceptible to consultants' advice and decided more likely against an oil-fired boiler when they spoke to an energy consultant. Their role is to "liaise directly with householders to identify and recommend retrofit technologies" [40]. This might be complemented by advice regarding implementation, use, and funding opportunities. Somewhat opposing are the findings of Berardi [41] who states that "their power to impose choices is often limited".

These advisors can have different organizational backgrounds as they might be from the public (e.g., NGOs) or the business sector (e.g., energy utilities, architecture, and engineering offices); the organizational context might affect both the depth of advice as well as their motivation and interest [40]. For instance, advisors from energy utilities have a certain commercial motivation which is not true for consultants from nonprofit organizations [43]. This might entail different levels of trust but also competency: if they work for another stakeholder like an energy utility, the energy consulting is considered as another aspect of the involvement of these stakeholders and explain their tie strength (multiplexity).

According to the report of [43], there are publicly funded advice providers (e.g., German Energy Agency dena, German Consumer Organisation, and Federal Office for Economic Affairs and Export Control) offering nation-wide product-neutral advice (mostly free of charge) in Germany. The services are offered via telephone, at offices or onsite. Advice from these independent institutions would diminish the above indicated concerns about trust in information from the private sector. It is likely that the decision-makers are aware of the services since they are promoted via several channels like the internet, brochures, and press releases [43]. This is supported by the report stating that "the problem is not to attract clients but to finance the advisers" [43]. To sum up, energy consultants can play an important role if decision-makers involve them in their process. Berardi [41] attributes medium to high power of energy consultant engineers over the adoption decisions. Probably they are most important at the interest and planning stage and less important at the awareness stage. Furthermore, the overall importance of consultants can also decrease with a higher number of previous adopters in the social network as already described for PV providers.

\subsubsection{Solar Initiatives}

While various stakeholders want to, at least partly, promote low-carbon technology adoption for commercial reasons, there are also stakeholders acting out of different motivations such as environmental purposes. Dewald and Truffer [44] term similar groups as solar initiatives. Explicitly in the context of residential PV, Noll et al. [58] refer to them as Solar Community Organizations and define them as "formal or informal organizations or citizen groups engaged in activities explicitly designed to encourage the adoption of residential rooftop solar PV". Frantzeskaki et al. [59] identified an important role of civil society groups in terms of diffusion, scaling up, and replication of sustainable innovations in and across cities. Noll et al. [58] found that Solar Community Organizations often cooperate with other stakeholders like universities or solar companies and described their role as "key organizational linkage that brings these resources together, communicates their availability and value to citizens, and pioneers coordinated programs to encourage adoption of PV."

Noll et al. [58] identified the local context as crucial for successful operations: "These organizations are unique in their ability to inform and influence consumer decision making because of the trust networks they hold through longstanding linkages with key individuals in local communities." Indeed, Sloot et al. [82] found that among Dutch community energy initiatives that also targeted photovoltaic uptake, involvement in these initiatives could uniquely explain intentions and behaviors toward PV adoption over and above 
any personal environmental motivations. Active peer effects and resulting passive peer effects are catalyzed through communities and both accelerate the adoption rate and partly explain the success of such organizations [58]. Besides the local embeddedness, the nature of these organizations makes the information to be perceived particularly trustworthy, and the credibility is backed up by expert knowledge from previous adopters who are part of the groups [58,83]. Dewald and Truffer [44] found that these initiatives were key intermediaries for "understanding early market formation success" in Germany and were explicitly founded "to compensate for coordination deficits in market formation". Besides, Noll et al. [58] highlight that in areas with little PV deployment, these initiatives play a greater role as a trustworthy source of information than in markets with a high number of adopters. It can be assumed that with a higher rate of adoption, civil society groups lose importance; however, as pointed out by Dewald and Truffer [44], solar initiatives operating in less mature markets (e.g., eastern parts of Germany and some middle and northern regions) still perceive their role as pivotal. Nevertheless, some PV with community storage models are only lucrative and possible in the right community [84]. This is also supported by McKenna [85]: due to the lack of economies of scale, the development of decentralized energy systems goes hand in hand with a trend towards community energy.

Thus, (a) the lesser the PV deployment within a decision-maker's surrounding and (b) the broader the range of activities that solar initiatives in particular or civil society groups in general offer, the stronger might be the influence on decision-makers at all stages. As a result of strong communication, campaigning and engagement, they might be particularly important at the awareness stage.

\subsubsection{Local and State- or National-Level Utility Companies}

Utility companies can occupy different roles. In addition to the private PV providers, utility companies can also provide low-carbon technologies (e.g., selling turnkey PV systems), have an advisory role as pointed out beforehand and related to their role as an energy provider, purchase electricity surpluses of residential PV systems [46]. Selvakkumaran and Ahlgren [52] link the presence of utility companies in solar PV retail to a decrease of the "uncertainty of long-term viability of solar PV", which in turn has a positive impact on the likelihood to adopt PV technology. This assumption is strengthened by the findings of Palm [46] which suggest that utilities that provide PV systems have an advantage in encouraging PV adoption in comparison to pure PV providers. He argues that decision-makers might attribute a higher credibility to the utility company in the context of low-carbon technologies and energy issues as well as ascribe a lower riskiness due to the fact that in general, utility companies have already been in the market for a long time and the core business is not related to the insecure PV market [46]. This is supported by Sommerfeld et al. [53] since respondents' answers indicated that they believed that the energy provider they bought the PV system from will still be there in the distant future and "they could have any problem rectified into future". Furthermore, Palm [46] mentions lower transaction costs resulting from a formerly established contractual relation between decision-maker and utility for the provision of power.

Additionally, local utilities were identified as being an important explanatory factor for a high number of PV adoption in five Swedish municipalities where electric utilities "have taken an active role in supporting PV [...] and disseminating information through seminars and their web pages" [46]. Moreover, these utilities have been acknowledged "as important influential forces" by participants [46]. Somewhat contrasting are the results of Rai et al. [18]: the median response for the importance of information from local utilities was moderate. Additionally, in comparison to installers, the respondents agreed less often that the local utility improves quality of information [18]. Regarding size and geographical context of utilities, the findings of Palm [46] suggest that small and locally operating firms promoting PV are more influential within the adoption process because low-diffusion municipalities were characterized by a domination of large state-level utilities like E.ON. or RWE in Germany. "The fact that the large utilities [... ] 
have apparently not been able to elevate local PV diffusion [...] indicate that PV sales need to be combined with other means of PV promotion" [46]. Reeves et al. [67] found that maturing markets go along with a more complex decision-making landscape, but the local information preference remained relatively stable in their study. This leads to a favorable position of the local utility companies in general and specifically in terms of adopter-targeted programs like bonuses or neighborhood open houses [67]. In Germany, local utilities are often municipal companies (e.g., Leipziger Stadtwerke) which "German cities can strategically use for energy innovation" [42]. Apart from the local focus, the public character of these utilities might alter the perception of decision-makers and influence for example attributed trust. Since local utilities might not exist in the same meaning in other countries as in Germany, the derivation of the influence strength may turn out differently for these countries. Beyond the German borders, however, the residential PV adoption also opens up new business models (e.g., renting rooftops, direct marketing, community solutions) for utilities $[49,86,87]$.

Considering the beginning of the adoption process, one spark event that was found to be substantial by Rai et al. [18] relates to a recent electricity rate increase which can be seen as an indirect influence of utility companies on decision-makers at the awareness stage. In addition, the final decision to install was strongly influenced by the protection against the electricity rate increases [18]. The driver is cost-saving by consuming self generated electricity since grid parity has already been reached [88]. Palm [46] provides another interesting insight from interviews with local and nonlocal utilities that emphasizes the crucial role at later stages. The representatives of the utilities stated being often approached by potential adopters before they sign a contract, although the installer usually deals with all paperwork and the general procedure does not require any contact. He therefore assumes that decision-makers consider the utilities as decisive experts [46].

It can be concluded that (a) local utilities are presumably more important than nationally operating utilities throughout the adoption process and (b) potentially more influential than pure PV providers due to higher attributed credibility (expertness and trustworthiness), (c) local utilities offer great potential to influence decision-makers during the whole process if they are perceptibly engaged in low carbon technology issues and (d) the influence might be further strengthened by peer effects from staff members. Due to the rather low share of utility companies offering turnkey PV systems and PV-related services in Germany, they are rated as moderately influential for German decision-makers; the influence strength might be strongest at the planning stage (redundant establishment of contact by decision-makers).

\subsection{Governmental Organizations, Authorities, or Other Institutions}

The literature results of the third stakeholder category are presented in the following.

\subsubsection{Federal and State Government}

Zhang et al. [89] found a significant negative influence of PV installation cost on the adoption decision, which gives governments a certain influence. A common way of subsidizing electric low-carbon technologies has been the implementation of feed-in tariffs (price-based policy instruments) and quota obligations based on tradable green certificates (quantity-based instruments), which makes the early adoption of PV a reasonable investment [90-93]. "Buy down" programs or installation subsidies, however, affect the initial cost of installation through the provision of capital grants and thus lower households' expenses regarding the purchase of a low-carbon technology adoption [91]. Beyond that, support can also be created in the form of laws (e.g., solar-friendly building regulations) or tax incentives (e.g., reduced VAT) $[44,58,62,86]$. Furthermore, soft loans for low-carbon technology investments can be provided by public funds [44]. In general, such supportive frameworks can be created at all levels of government $[44,62]$. 
A quota obligation is "less efficient from a societal point-of view compared to the other instruments analysed such as feed-in tariffs" [90].

To what extent financial support measures drive adoption decision making, is reflected by the following: Rode and Müller [51] related a decline in PV adoption in Germany in 2004 to changes in the subsidy system. Dewald and Truffer [44] view such support schemes as a precondition for the development of low-carbon technology markets in the first place. This is supported by the findings of Beise [63]; he found that in Japan and Germany, the successful diffusion of PV systems can be traced back to the provision of governmental financial support. Kwan [61] found a positive influence on PV adoption when there was a larger amount of available financial incentives in the U.S., and Wüstenhagen and Bilharz [64] identified feed-in tariffs as the main driver of PV diffusion in Germany. More recent findings, however, slightly weaken the influence of feed-in tariffs since grid parity has been achieved in 2012 [55]. Regarding the local level, de Groote et al. [62] found that local policies in terms of financial support scheme were an significant explanatory variable for high rates of PV adoption in Belgium. Generally, Ragwitz and Steinhilber conclude "that support schemes, which are technology-specific, and those that avoid unnecessary risks in project revenues, are more effective and efficient than technology-neutral support schemes, or schemes with higher revenue risk" [94]. The literature shows that the governmental programs and incentives can matter in driving adoption decisions, but it may be more likely that the programs can influence adoption decisions after being used as "leverage" by other stakeholders.

\subsubsection{Funding Bodies and Financial Institutions}

Regional subsidies as well as consultation services are provided by local development banks at state level (e.g., Sächsische Aufbaubank in Germany) whose influence depends on what each state offers, and thus strongly depends on the place of residence of decision-makers in Germany as well as the governmental programs and incentives provided. Today, these regional subsidies also strongly depend on the low-carbon technology and installation size [95].

In Germany, in addition to state-level funding bodies, the important stakeholder regarding the provision of soft loans is the federal funding body Kreditanstalt für Wiederaufbau. Such soft loans for low-carbon technologies are handled, however, by financial partners (e.g., commercial banks, direct banks, insurance companies, or other financial agents) operating at the local level [96]. Some local private banks even started to provide their own soft loans for energy efficiency refurbishments for decision-makers who "wish to avoid the high bureaucratic requirements occurring when applying for low-interest loans/subsidies of public funding institutions" [42]. However, this local financing offer has not been taken up by citizens as expected [42].

Interestingly, Noll et al. [58] found that decision-makers preferred financing options provided by local "nearby" financial institutions since they are perceived to be "more accessible and trustworthy" and found a positive influence of local options on adoption. Nevertheless, since local financial institutions are anyway supposed to be actively involved in the decision-making process in Germany, it can be assumed that this procedure affects decision-making in a positive way (or at least not in a negative one). The application of any support needs to be submitted before physical modifications (e.g., installation, construction works) take place [95] which is why it can be concluded that these stakeholders are involved up to the (early) planning stage.

\subsubsection{Local Governments}

Local governments have a broad range of functions and scope of action due to the right of self-government [97], which renders municipalities especially powerful in taking voluntary climate action. In this context, municipalities can act as (1) consumers and role models, (2) planners and regulators 
as well as (3) advisors and promoters [98]: If a municipality installs low-carbon technologies such as PV on municipal buildings, it acts as a role model for citizens. Defining energy standards for new buildings reflects the role as planner and regulator, and providing information in terms of low-carbon technologies (e.g., online, energy advice centers) or subsidy schemes belongs to the role as advisor or promoter. For instance, Jager [60] examined the city of Groningen which engaged proactively to stimulate PV adoption. The municipality advertised in the local newspaper for several information meetings and organized a central handling of grant applications which both helped to increase PV adoption since technical and bureaucratic barriers were reduced [60]. This shows that there is much more that municipalities can engage in, apart from financial support.

An advantage of local governments can be found in less physical distance to decision-makers. They can probably exert more influence and have a wider scope of action than higher levels of government. Nevertheless, residential PV systems do usually not require a building permit in Germany (regulated at state level). Bale et al. [28] attribute a key role to local authorities since they assume them (a) to be a "trusted source of information" compared to energy companies and (b) to "have local knowledge of the needs of their residents and communities (which central government does not)". However, Berardi [41] found that efforts of Italian municipalities regarding the diffusion of energy-saving technologies were low and he assumed that poor local government engagement undermines political efforts and support measures at higher levels (state or federal). In this context, it can be concluded that the local governments play a substantial role at all process stages.

\subsection{Other Stakeholders}

The literature results of the fourth stakeholder category are presented in the following.

\subsubsection{Building Professionals}

Another stakeholder group consisting of actors in the construction industry comes into play when decision-makers plan to or already construct a building or undertake renovation measures. This includes designers, architects, builders, general contractors, and other similar actors. Parag and Janda [66] refer to building professionals as "middle actors" between technology and decision-maker while specifying that builders "currently serve a relatively weak but potentially important middle role". Davies and Osmani [65] recognized that architects have an important role "owing to their leadership and significant involvement in the initial briefing, conceptual and design development phases of a project". Special importance is attributed to architects in terms of building-integrated photovoltaic [38]. Zedan and Miller [56] considered designers and builders to have strong influence. However, building professionals cannot fully make use of this potential because of their own deficits in low-carbon technology knowledge [66].

Another inhibiting influence was described by Curtius [38]. He termed architects as "key gatekeepers" within the market and identified them to be often reluctant towards this technology because "PV systems are apparently not compatible with the traditions and past experiences of many architects" [38]. Thus, they often lack awareness and knowledge [38]. A similar result was found by Davies and Osmani [65] in the UK: low carbon housing refurbishment design is generally no priority objective for architects and lacking legislative drivers to engage stronger in this field contribute to their low motivation and efforts. Berardi [41] also found that stakeholders having power to select low-carbon technologies in construction projects often lack interest in their adoption. Even if the potential is only used to a limited extent today, architects and building professionals in general could occupy a facilitating role for low-carbon technologies and influence decision-makers significantly.

Building professionals could occupy an important role at all stages of decision-making by informing, advising, and implementing low carbon technologies through subcontractors. However, in reality, 
they seem to have an inhibiting influence on decision-makers throughout the adoption process and make less use of their favorable position unless the circumstances have changed in recent years. Nevertheless, this stakeholder group is ranked as potentially influential at all stages due to its favorable position towards the decision-maker but weakened through their lacking interest and efforts in this topic.

\subsubsection{Scientists and Research Institutions}

Numerous (social) scientific projects have focused on the question of low-carbon technologies and their uptake by individuals and communities [18,99], raising the question if scientists and research institutions can be relevant stakeholders in the adoption process. On the one hand, scientific research's influence may be rather small and indirect, considering that scientific research output typically does not aim to directly target and inform household decision-makers. Thus, the scientific communities' primarily theoretical approaches need to be differentiated from actual influence on the adoption process of residential decision-makers. On the other hand, while mainly generating output that can inform low-carbon technology adoption-relevant policy making, empirical social scientific research often directly affects the studied samples through questionnaires, interviews, or other methods used to generate scientific insights [82,100,101]. Other areas of (energy) research have shown that people who participate in scientific studies may indeed behave differently as an effect of simply being observed or participating in a study (resemblent of the Hawthorne effect; cf. [102,103]), and such reactivity or demand characteristics effects may be stronger the more intrusive studies are [104]. For example, researchers conducting interviews among community energy initiatives or repeatedly sending out questionnaires to households might inadvertently exert some degree of social influence on the recipients' behavior. Yet, little research has directly studied the possibility and extent of such influences from scientists and research institutions, thus not allowing any confident conclusions.

\subsection{Media Channels}

The fifth category media is especially important regarding the dissemination of information and plays a special role as they represent channels of information instead of proper stakeholders. In the literature, there are also channels of information mentioned by decision-makers like information obtained through "googling around" which does not reveal the real stakeholder but plays a substantial part of the information procurement [5]. Rogers [1] suggests that information conveyed through mass media channels is relatively more important at the beginning of the adoption process and therefore loses importance as the decision-making proceeds. Furthermore, he values mass media as "the most rapid and efficient means of informing an audience of potential adopters about the existence of an innovation" [1].

It is assumed that channels like television, radio, newspaper, and magazines in printed form or online, including advertisement, are most important at the awareness stage and less important at later stages. Specialist media like trade and scientific journals reporting about energy-related issues (e.g., Photon in terms of PV) are hypothesized to be most relevant at the interest stage. According to the study of Southwell et al. [68], social networking sites like Facebook or Twitter are reported as being of minor importance. It was concluded that only 3\% of the respondents of the U.S. study who even stated that they share energy related information share relevant information there. However, it can be assumed that a higher usage of social media in recent years also leads to a higher importance. Online resources that cannot be exactly determined and are usually found by "googling around", were for example rated to be moderately important in a survey among U.S. PV adopters [67], supported by the study of Rai et al. [18] who found a similar response. Interestingly, Palm [46] also found the preference for local web pages and media sources. Rogers' [1] theory differs somewhat since he argues that the relevance of localite channels is 
relatively higher at the interest stage but nonlocal or cosmopolite channels play a relatively greater role at the awareness stage.

\section{Discussion}

\subsection{Stakeholder Dynamics Assessment}

The literature review reveals that household decision-makers are surrounded by a complex network of stakeholders and influence dynamics. The findings show a multitude of different stakeholders that can be potentially relevant in influencing adoption decisions. In this regard, the increase of stakeholder dynamics contribute to a greater level of certainty for the decision-maker and the influence of a certain stakeholder changes with the stage of the decision-making process. Thereby the absolute influence of different stakeholders decreases as the process moves forward and instead becomes more concentrated on single stakeholders. As expected, generally there is a shift from informal knowledge at the awareness stage to concrete, economic, and technical knowledge needed at later stages. This automatically entails the involvement of more specialized information sources and thus a change in the set of relevant stakeholders. Additionally, the importance of the stakeholders for the decision-maker is partly related to the stakeholder attributes. The perceived stakeholder attributes seem to have an effect on the strength of the dynamics at different stages of the decision-making process.

Taking a closer look at the individual stakeholders, the results regarding the social network show that emotionally and at its best spatially closest stakeholders such as family members and friends of the social network are the most influential ones. It can be assumed that there is a dependency of active peer effects and likeability. Furthermore, the local utilities have an influential role along the decision-making process. This stakeholder is perceived as more influential than national utilities because of the local character, trustworthiness but also power. Regarding energy advisors, literature stresses the favorable position and thereto related influence potential towards an informed adoption decision. A similar effect applies to the gatekeeping influence of building professionals. Their strong influence potential is nowadays, however, only used to a limited extent. In contrast, solar initiatives and civil society groups exert a significant influence on the decision. The overall importance of the intermediary media seems to be moderate with varying influence strengths in terms of media channel and process stages.

Thereby, the results from the literature review might be slightly biased because of the very heterogeneous study designs and more importantly different geographical settings from which the stakeholder dynamics have been derived. Furthermore, due to the evolving PV market and external environment as such, results from studies that have taken place in early market phases might be different from today's point of view. Moreover, the studies of the literature review were mainly based on correlation evidence. Therefore, we cannot draw causal conclusions about our findings.

\subsection{Procedural Egocentric Perspective}

Based on the presented literature findings, an assessment of overall relative influence strengths per decision stage is done while emphasizing that it is a rather rough assessment and pointing at the less gradual and more fluent course of decision making in reality. In this context, stakeholder influences along the decision-making process are visualized with the help of egocentric network maps.

The ego network visualization in terms of PV decision-making in this paper shall depict all relevant dyadic ties (backed up by the proposed attributes) of a decision-maker at the household level to alters during the decision-making process. The alters represent the identified and analyzed stakeholders. The ego network is visualized by means of a network map which allows to depict (a) differences in influence strengths through concentric circles around the decision-maker and (b) perceived stakeholder attributes 
through actor pies, (c) grouped by stakeholder category through the division into five sectors. A tie is depicted in the map as soon as the ego is influenced in any way in terms of the PV decision by an alter. Consequently, ties represent (positive and negative) influences. The stronger a tie, the higher a stakeholder's influence on the decision-maker and the closer the stakeholder to the decision maker. The assessment is based on the following indicators presented in the literature analysis: the predictors source of relationship, extent of multiplexity (including functions), as well as stakeholder attributes (power, trustworthiness, expertness), and relational attributes (likability, closeness). However, for instance a stakeholder might be highly influential due to the attribute power without showing a high extent of multiplexity. Thus, all factors underlying tie strength need to be thoroughly taken into account. The aim is to value positive and negative influence strength of one stakeholder in proportion to other stakeholder. The alters encompass all stakeholders identified and analyzed. The stakeholder dynamics shall be reflected by building a distinct ego network for each process stage. These networks depict stage-specific stakeholder influences which allows us to capture the changing salience, expressed by the relative influence strength, of different stakeholders along the process.

\subsubsection{Awareness Stage}

In the beginning of the process, the decision-maker is most likely strongly influenced by the social network in general and in particular from his or her neighbors, friends/acquaintances, and family. It is assumed that neighbors to whom decision-makers already had some relationship are the most influential stakeholders in the social network. The extraordinary influence of solar initiatives needs to be highlighted due to the unique intermediary and networking functions they fulfill. PV providers are rated as influential as the salient stakeholders of the social network. Local utilities probably exert moderate influence while state-level utilities, PV manufacturers, energy advisors, and NPOs/associations are rather invisible at this stage. The local government can also raise awareness whereas state and national governments and funding bodies/financial institutions are yet less relevant. The same counts for scientists and building professionals. In the section media, the most important channels are advertisement and mass media. A synthesized overview of the stakeholder dynamics at the awareness stage is illustrated in Figure 3.

\subsubsection{Interest Stage}

While the overall social network influences are relatively stable and only slightly decrease, there are other stakeholders gaining influence: Energy advisors and NPOs/associations become more important due to the higher relevance of advisory needs. Similar is the development of influences of funding bodies/financial institutions and state and national governments which are also more important than at the awareness stage. While online sources ("googling around") and probably subject-specific journals become more important, the influence of mass media fades. A synthesized overview of the stakeholder dynamics at the interest stage is illustrated in Figure 4.

\subsubsection{Planning Stage}

The slight decrease of the overall social network continues whereas stakeholders from the energy system and related to PV-specific services may become more important as a logic consequence of more concrete engagement of the decision-maker in purchasing a PV system. This holds in particular true for PV providers and local utility companies and energy advisors or NPOs/associations. Furthermore, local governments are more influential as a result of power when it comes to building permits. In addition, financing the PV system becomes more important and consequently also financial institutions and funding bodies. The other stakeholders and media's influence remain unaltered. A synthesized overview of the stakeholder dynamics at the planning stage is illustrated in Figure 5. 

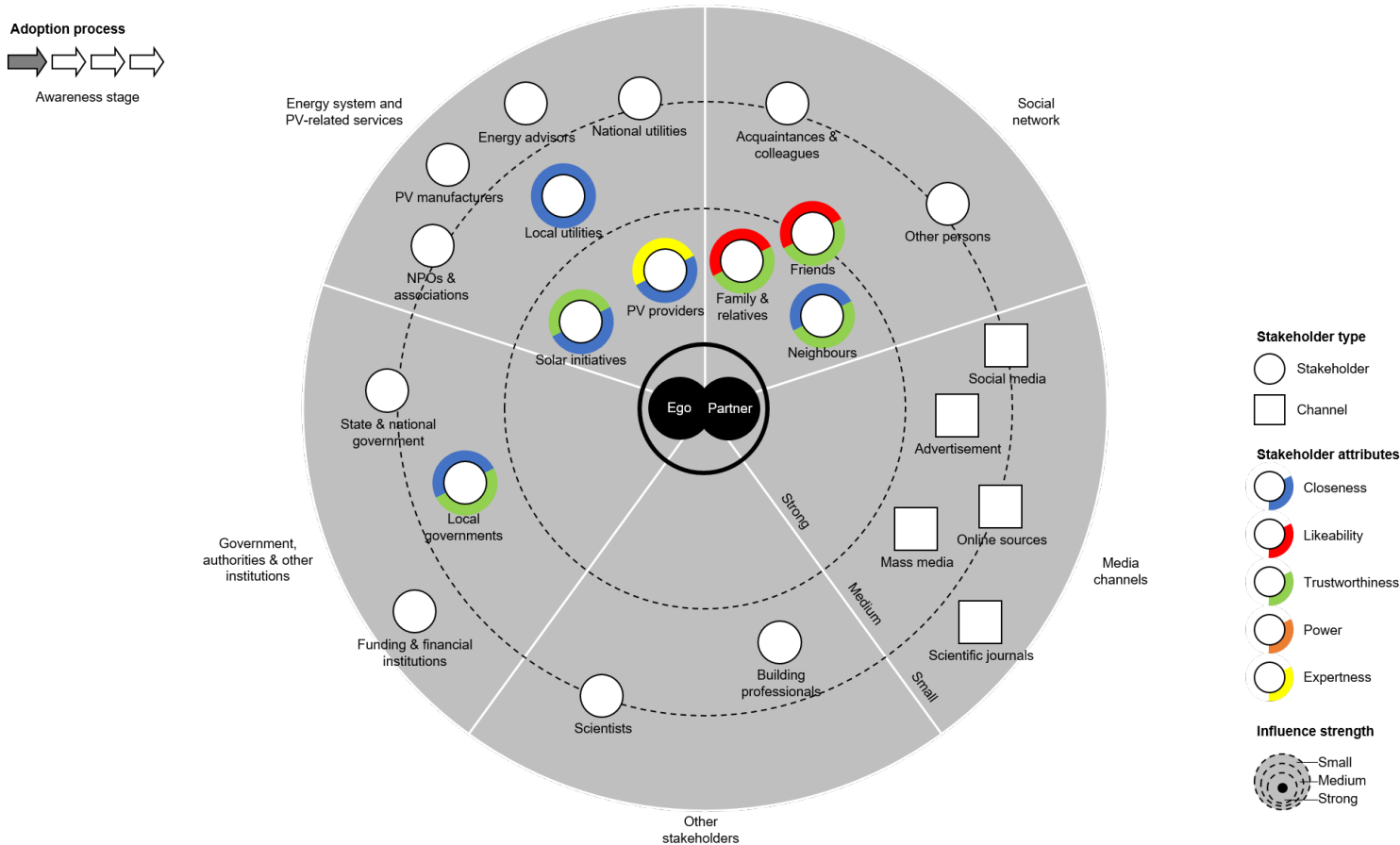

Figure 3. Visual representation of the egocentric network of the stakeholder dynamics at the awareness stage. The focus is on residential PV adoption from the perspective of the household decision-maker (own illustration).
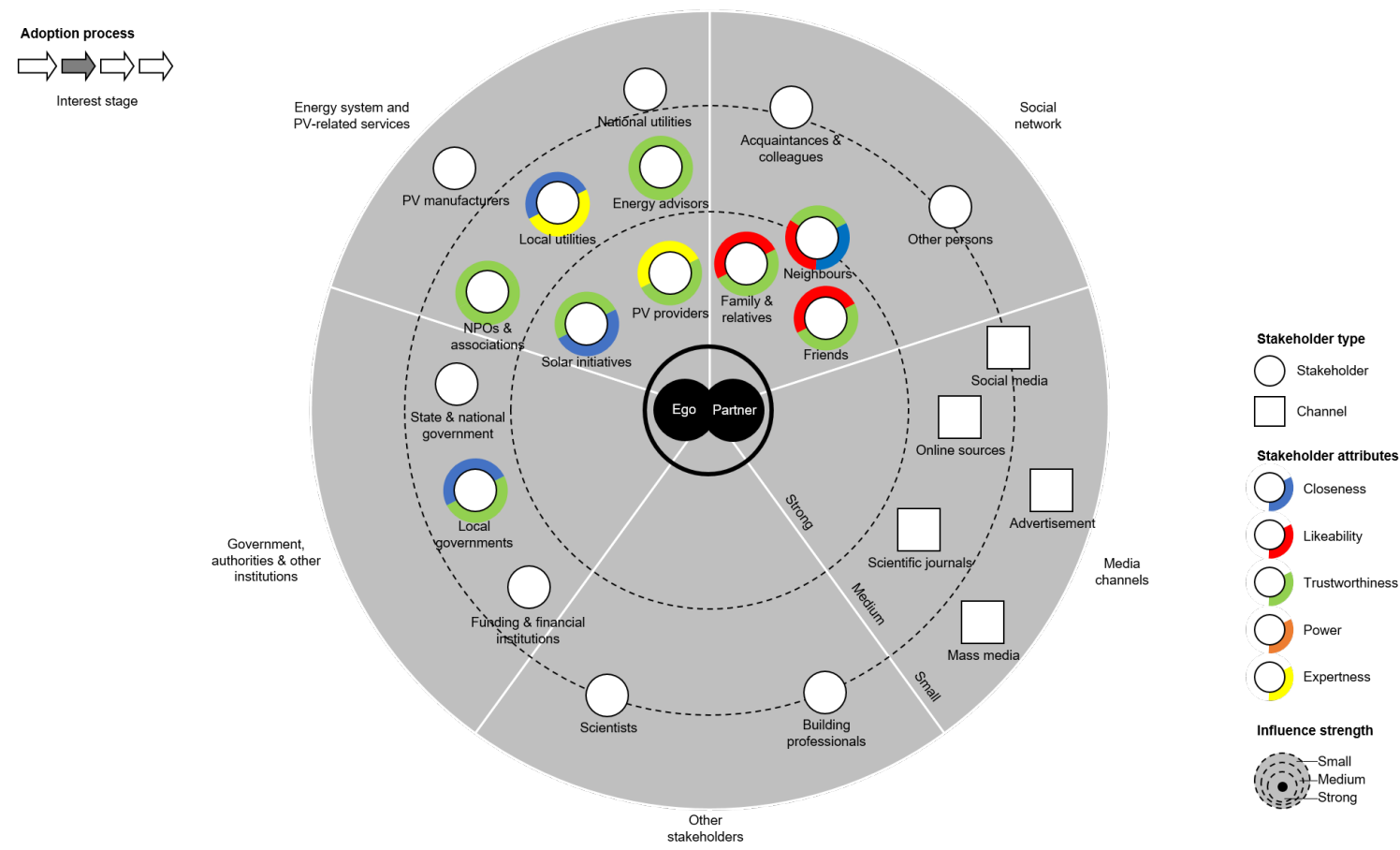

Figure 4. Visual representation of the egocentric network of the stakeholder dynamics at the interest stage. The focus is on residential PV adoption from the perspective of the household decision-maker (own illustration). 


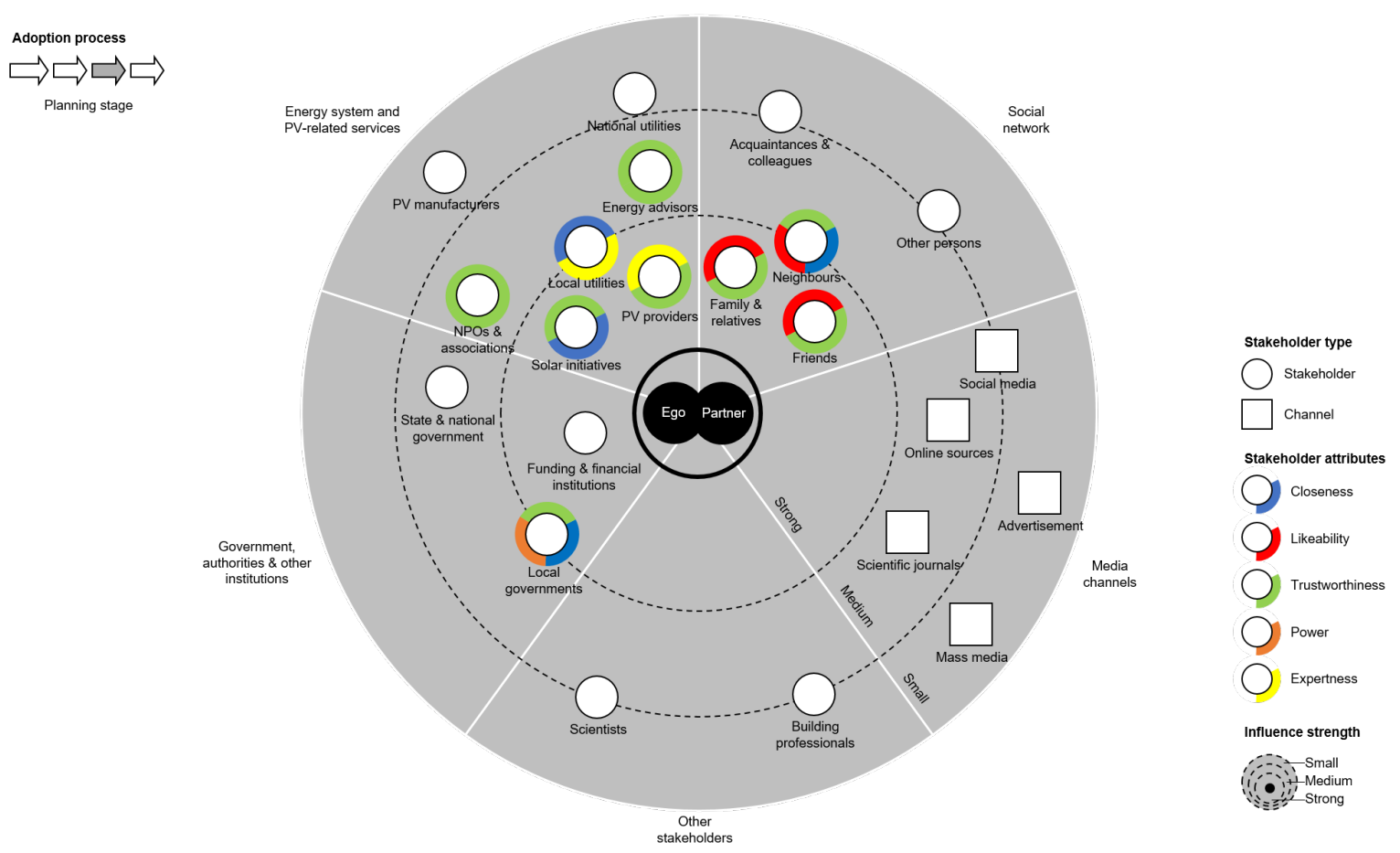

Figure 5. Visual representation of the egocentric network of the stakeholder dynamics at the planning stage. The focus is on residential PV adoption from the perspective of the household decision-maker (own illustration).

\subsection{Theoretical and Practical Implications}

The presented findings demonstrate that, indeed, the stakeholder landscape in terms of low-carbon technology decision making is highly dynamic on different levels. As the stakeholder literature suggests, stakeholder categories, roles, and influence strength vary along the decision-making process. Besides, the results based on the present body of literature reveal several circumstances that condition stakeholder landscapes and their dynamics as well as lead to stakeholder dynamics from a general point of view:

1. The (a) level of diffusion of the low-carbon technology has an impact on how influential different stakeholders are (e.g., relevance of social network) but also (b) the share of previous adopters in a decision-maker's social network or the knowledge about the technology itself conditions the importance of other stakeholders (e.g., PV providers).

2. There are differences between (a) rural and nonrural adoption behaviour (e.g., regarding peer effects) but also in terms of (b) the living and concrete situation of the decision-maker (e.g., acquisition of a PV system while renovating or building a house vs. decoupled adoption decision).

3. The location of the decision-maker determines (a) the set of available stakeholders (e.g., availability of solar initiatives in a particular area), (b) the relevance of some stakeholders (e.g., state-level funding bodies), and (c) the salience of these stakeholders due to highly varying efforts within the same stakeholder group.

4. The (a) adoption decision stage of the decision-maker is important for the effectiveness of the stakeholder dynamics and (b) the set of stakeholders influencing decision-makers at early stages (awareness stage and early interest stage) probably condition how influential and important different stakeholders are at subsequent stages.

5. The findings suggest that decision-makers (a) particularly value certain stakeholder attributes (e.g., a neighbouring friend of the decision-maker works at a solar company leads to higher influence 
due to tie multiplexity) but also (b) attach different importance to different stakeholder attributes depending on the decision stage. Thereby, the local "versions" of a stakeholder (e.g., local vs. national utility; local governments) is seen in a particular way because of varying attributed levels of trust and other scope of actions.

These highly time- and in particular location-bound conditions make it especially difficult to assess the relative importance of stakeholders (a) along the decision-making process and (b) across stakeholders. Yet, taking these dynamics into consideration allows public actors, such as policy makers at the local level or other advocate groups, to take more effective and targeted action towards promoting the adoption of low-carbon technologies. The findings thus have important implications, as they emphasize the importance of targeted campaigns rather than one-size-fits-all approaches. Practitioners can likely increase the effectiveness of adoption campaigns by considering (a) the desired behavior change or decision-making stage (e.g., build awareness or influence purchasing decisions) and (b) the specific target group (e.g., longtime house owners or prospective building owners) in order to identify stakeholders that may be most influential at a given stage. With regard to the first point, information campaigns to promote PV adoption should be designed towards a specific stage in individuals' decision-making process and thus avoid an unnecessary overload with irrelevant information. For example, information at an early awareness stage likely needs to be more general, communicating the overall benefit of PV for the environment and general personal (e.g., financial) benefits. Campaigns using social influence approaches could further focus on communicating a social norm of PV adoption becoming increasingly frequent. Too specific information may be seen as distracting at this early stage of decision-making. However, at a later stage, in particular the stage of the actual formal decision to adopt, information needs of potential adopters are likely more specific and expert knowledge may become more relevant. Therefore, the role of PV installers but also providers of financial subsidies likely increases, as these stakeholders can provide information on specific steps to take as well as specific (e.g., financial) consequences after the formal adoption decision; such information will likely support the formal decision to adopt at this late stage.

From a practical perspective, our insights further suggest that the relative importance of different stakeholders shifts across the adoption decision process, and campaigns to promote PV adoption could thus account for this by considering and involving multiple stakeholders within a campaign. For example, local municipalities aiming to increase PV adoption could target entire local neighborhoods at once by direct marketing and at the same time collaborate with PV installers that provide expert information. The establishment (or pre-existence) of solar communities initiatives would of course be ideal, as these initiatives can create more networking opportunities for people to exchange and confirm information with people from their own network, which we find an important social influence factor in our review. Yet, besides solar community initiatives, actors such as municipalities could organize more informal networking opportunities, such as community social events. This would ensure that supporting information is not only presented in an anonymous bilateral way but that it allows for more effective social influence to support individuals' adoption decisions.

\subsection{Future Work}

Future research can build on these findings to further clarify the role stakeholders play in the adoption process and, crucially, how to harness this social influence effectively to support individuals' decision making. In particular, research could further investigate the processes by which stakeholder influence operates. Further data could also be gathered in different locations to establish the generalizability of stakeholder dynamics across different populations or cultures. A more detailed investigation of the proposed stakeholder and relational attributes expertness, trustworthiness, power, likeability, and closeness is also necessary. Applying different approaches such as in-depth interviews, focus groups, and also 
representative surveys with decision-makers could be relevant to move this research forward. Finally, the findings should also be incorporated into energy system models for managing and predicting low carbon technology adoptions (e.g., agent-based models of technology adoption [105]).

\section{Conclusions}

This research provides insights into the complex and dynamic external environment in which decision-makers operate. Its main contribution is to define the stakeholder landscape involved in low-carbon technology decision making and review the social influence that stakeholders bring about in the decision-making process. The findings from a literature review indicated a multitude of different stakeholders can influence the decision-making process regarding residential PV adoption. Moreover, the stakeholder influences are dynamic on several levels, and especially time- and location-bound factors affect the impact. Depending on the decision-making stage, the influence strength of various stakeholders varies. In particular, findings indicate that social influence gradually shifts from many different stakeholders to a more concentrated number of core stakeholders that influence the decision making later on. These insights suggest that PV adoption decisions may be more reliably predicted if a process perspective is taken into account that not only distinguished between different stakeholders but considers their dynamic importance along the adoption decision stages. Another important insight from this study is that household decision-makers are mainly influenced by stakeholders from their own social network, such as family, neighbors, and friends, next to PV-related services, such as providers and civil society groups. Thereby, the perceived closeness and likeability of a stakeholder indicate a higher level of influence because of the greater trust involved. These findings provide a novel synthesis of the literature with special regards to the importance of social influences across different stages of households' decision making and have important implications for how PV adoption can be both understood and stimulated in practice. Overall, the existing literature indicates that different stakeholders play an important role throughout the adoption process, suggesting that actively considering and encouraging social interactions between stakeholders and potential PV adopters can be fruitful to accelerate PV adoption.

Author Contributions: Conceptualization, F.S. and I.D.; methodology, I.D. and F.S.; investigation, I.D., F.S., and D.S.; writing-original draft preparation, F.S., I.D., D.S., R.M., T.B.; writing-review and editing, F.S., I.D., D.S.; visualization, I.D. and F.S.; supervision, F.S.; project administration, T.B. and R.M.; funding acquisition, F.S., T.B., R.M.; All authors have read and agreed to the published version of the manuscript.

Funding: Fabian Scheller kindly acknowledges the financial support support of the European Union's Horizon 2020 research and innovation programme under the Marie Sklodowska-Curie grant agreement no. 713683 (COFUNDfellowsDTU). Isabel Doser received funding from the project SUSIC (Smart Utilities and Sustainable Infrastructure Change) with the project number 1722 0710. This study is financed by the Saxon State government out of the State budget approved by the Saxon State Parliament.

Acknowledgments: For valuable feedback, the authors wish to thank the anonymous reviewer and the associate editor.

Conflicts of Interest: The authors declare no conflict of interest. The funders had no role in the design of the study; in the collection, analyses, or interpretation of data; in the writing of the manuscript, or in the decision to publish the results.

\section{References}

1. Rogers, E.M. Diffusion of Innovations, 5th ed.; Free Press: New York, NY, USA, 2003.

2. Straub, E.T. Understanding Technology Adoption: Theory and Future Directions for Informal Learning. Rev. Educ. Res. 2009, 79, 625-649. [CrossRef]

3. Wilson, C.; Dowlatabadi, H. Models of Decision Making and Residential Energy Use. Annu. Rev. Environ. Resour. 2007, 32, 169-203. [CrossRef] 
4. Wolske, K.S.; Stern, P.C.; Dietz, T. Explaining interest in adopting residential solar photovoltaic systems in the United States: Toward an integration of behavioral theories. Energy Res. Soc. Sci. 2017, 25, 134-151. [CrossRef]

5. Palm, J.; Eriksson, E. Residential solar electricity adoption: How households in Sweden search for and use information. Energy Sustain. Soc. 2018, 8, 6. [CrossRef]

6. Sierzchula, W.; Bakker, S.; Maat, K.; van Wee, B. The influence of financial incentives and other socio-economic factors on electric vehicle adoption. Energy Policy 2014, 68, 183-194. [CrossRef]

7. Niamir, L.; Filatova, T.; Voinov, A.; Bressers, H. Transition to low-carbon economy: Assessing cumulative impacts of individual behavioral changes. Energy Policy 2018, 118, 325-345. [CrossRef]

8. Palm, A. Peer effects in residential solar photovoltaics adoption-A mixed methods study of Swedish users. Energy Res. Soc. Sci. 2017, 26, 1-10. [CrossRef]

9. Ryan, B.; Gross, N.C. The diffusion of hybrid seed corn in two Iowa communities. Rural Sociol. 1943, 8, 15.

10. Valente, T.W.; Rogers, E.M. The Origins and Development of the Diffusion of Innovations Paradigm as an Example of Scientific Growth. Sci. Commun. 2016, 16, 242-273. [CrossRef]

11. Axsen, J.; Kurani, K.S. Social Influence, Consumer Behavior, and Low-Carbon Energy Transitions. Annu. Rev. Environ. Resour. 2012, 37, 311-340. [CrossRef]

12. Labay, D.G.; Kinnear, T.C. Exploring the Consumer Decision Process in the Adoption of Solar Energy Systems. J. Consum. Res. 1981, 8, 271-278. [CrossRef]

13. MacPherson, R.; Lange, I. Determinants of green electricity tariff uptake in the UK. Energy Policy 2013, 62, 920-933. [CrossRef]

14. Ozaki, R. Adopting Sustainable Innovation: What Makes Consumers Sign up to Green Electricity? Bus. Strategy Environ. 2011, 20, 1-17. [CrossRef]

15. Wilson, C.; Pettifor, H.; Chryssochoidis, G. Quantitative modelling of why and how homeowners decide to renovate energy efficiently. Appl. Energy 2018, 212, 1333-1344. [CrossRef]

16. Arts, J.W.; Frambach, R.T.; Bijmolt, T.H. Generalizations on consumer innovation adoption: A meta-analysis on drivers of intention and behavior. Int. J. Res. Mark. 2011, 28, 134-144. [CrossRef]

17. Ajzen, I.; Fishbein, M. The Influence of Attitudes on Behavior. In The handbook of attitudes; Lawrence Erlbaum Associates Publishers: Mahwah, NJ, USA, 2005; pp. 173-221.

18. Rai, V.; Reeves, D.C.; Margolis, R. Overcoming barriers and uncertainties in the adoption of residential solar PV. Renew. Energy 2016, 89, 498-505. [CrossRef]

19. Geels, F.W.; Schwanen, T.; Sorrell, S.; Jenkins, K.; Sovacool, B.K. Reducing energy demand through low carbon innovation: A sociotechnical transitions perspective and thirteen research debates. Energy Res. Soc. Sci. 2018, 40, 23-35. [CrossRef]

20. Mitchell, R.K.; Agle, B.R.; Wood, D.J. Toward a theory of stakeholder identification and salience: Defining the principle of who and what really counts. Acad. Manag. Rev. 1997, 22, 853-886. [CrossRef]

21. Curtis, J.; McCoy, D.; Aravena, C. Heating system upgrades: The role of knowledge, socio-demographics, building attributes and energy infrastructure. Energy Policy 2018, 120, 183-196. [CrossRef]

22. Reed, M.S.; Graves, A.; Dandy, N.; Posthumus, H.; Hubacek, K.; Morris, J.; Prell, C.; Quinn, C.H.; Stringer, L.C. Who's in and why? A typology of stakeholder analysis methods for natural resource management. J. Environ. Manag. 2009, 90, 1933-1949. [CrossRef]

23. Kamal, M.; Weerakkody, V.; Irani, Z. Analyzing the role of stakeholders in the adoption of technology integration solutions in UK local government: An exploratory study. Gov. Inf. Q. 2011, 28, 200-210. [CrossRef]

24. Postema, T. A method to evaluate the role of stakeholder dynamics in IT based innovation adoption processes. World Hosp. Health Serv. Off. J. Int. Hosp. Fed. 2010, 46, 12-15.

25. Berlo, D.K.; Lemert, J.B.; Mertz, R.J. Dimensions for evaluating the acceptability of message sources. Public Opin. Q. 1969, 33, 563-576. [CrossRef]

26. Van der Waldt, D.; Van Loggerenberg, M.; Wehmeyer, L. Celebrity endorsements versus created spokespersons in advertising: A survey among students. S. Afr. J. Econ. Manag. Sci. 2009, 12, 100-114. [CrossRef]

27. McGinnies, E.; Ward, C.D. Better liked than right: Trustworthiness and expertise as factors in credibility. Personal. Soc. Psychol. Bull. 1980, 6, 467-472. [CrossRef] 
28. Bale, C.S.; McCullen, N.J.; Foxon, T.J.; Rucklidge, A.M.; Gale, W.F. Harnessing social networks for promoting adoption of energy technologies in the domestic sector. Energy Policy 2013, 63, 833-844. [CrossRef]

29. Nesler, M.S.; Aguinis, H.; Quigley, B.M.; Tedeschi, J.T. The Effect of Credibility on Perceived Power 1. J. Appl. Soc. Psychol. 1993, 23, 1407-1425. [CrossRef]

30. Friedman, A.L.; Miles, S. Stakeholders: Theory and Practice; Oxford University Press on Demand: Oxford, UK, 2006.

31. van der Lei, T.E. A categorization of actor analysis methods. In Next Generation Infrastructure systems for Eco-Cities; IEEE: Shenzhen, China, 2010, pp. 1-7. [CrossRef]

32. Donaldson, T.; Preston, L.E. The Stakeholder Theory of the Corporation: Concepts, Evidence, and Implications. Acad. Manag. Rev. 1995, 20, 65-91. [CrossRef]

33. Wassermann, S.; Faust, K. Social Network Analysis Methods and Applications: Structural Analysis in the Social Sciences; Cambridge University Press: Cambridge, UK, 1994.

34. Perry, B.L.; Pescosolido, B.A.; Borgatti, S.P. Egocentric Network Analysis; Cambridge University Press: Cambridge, UK, 2018; doi:10.1017/9781316443255. [CrossRef]

35. Marin, A.; Wellman, B. Social network analysis: An introduction. SAGE Handb. Soc. Netw. Anal. $2011,11,11-25$. [CrossRef]

36. IEA. Renewables 2019: Market Analysis and Forecast from 2019 to 2024; IEA: San Francisco, USA, 2019.

37. Varvasovszky, Z.; Brugha, R. A stakeholder analysis. Health Policy Plan. 2000, 15, 338-345. [CrossRef]

38. Curtius, H.C. Diffusion of Solar Photovoltaics: Consumer Preferences, Peer Effects and Implications for Clean Energy Marketing. Ph.D. Thesis, University of St. Gallen, St. Gallen, Switzerland, 2018.

39. Alipour, M.; Salim, H.; Stewart, R.A.; Sahin, O. Predictors, taxonomy of predictors, and correlations of predictors with the decision behaviour of residential solar photovoltaics adoption: A review. Renew. Sustain. Energy Rev. 2020, 123, 109749. [CrossRef]

40. Owen, A.; Mitchell, G.; Gouldson, A. Unseen influence-The role of low carbon retrofit advisers and installers in the adoption and use of domestic energy technology. Energy Policy 2014, 73, 169-179. [CrossRef]

41. Berardi, U. Stakeholders' influence on the adoption of energy-saving technologies in Italian homes. Energy Policy 2013, 60, 520-530. [CrossRef]

42. Huber, A. Composite Case Study Bottrop. Available online: https://www.eifer.kit.edu/IMG/pdf/EIFER_ Report_Bottrop.pdf (accessed on 01 November 2020).

43. Catrin, M.; Francesce, B.; Loic, L.; Christiane, E.; Christine, Ö.; Erika, B.; Erik, A.; Marjana, Š.; Ivanka, P.; Raphaël, C.; et al. Energy advice in Europe 2007-A Review of Current Practice in Advice on Sustainable Energy in the Countries of the European Union, Severn Wye Energy Agency: Gloucestershire, UK, 2007.

44. Dewald, U.; Truffer, B. The Local Sources of Market Formation: Explaining Regional Growth Differentials in German Photovoltaic Markets. Eur. Plan. Stud. 2012, 20, 397-420. [CrossRef]

45. Verhoog, M. Steuerung von Akteuren und Entscheidungen in Baunetzwerken: Eine Netzwerkanalytische Untersuchung zur Sanierungsentscheidung im Haushalt; Springer: Berlin/Heidelberg, Germany, 2017.

46. Palm, A. Local factors driving the diffusion of solar photovoltaics in Sweden: A case study of five municipalities in an early market. Energy Res. Soc. Sci. 2016, 14, 1-12. [CrossRef]

47. Bollinger, B.; Gillingham, K. Peer Effects in the Diffusion of Solar Photovoltaic Panels. Mark. Sci. 2012, 31, 900-912. [CrossRef]

48. Rai, V.; Sigrin, B. Diffusion of environmentally-friendly energy technologies: Buy versus lease differences in residential PV markets. Environ. Res. Lett. 2013, 8, 014022. [CrossRef]

49. Richter, L.L. Social Effects in the Diffusion of solar Photovoltaic Technology in the UK. Apollo 2013. [CrossRef]

50. Graziano, M.; Gillingham, K. Spatial patterns of solar photovoltaic system adoption: The influence of neighbors and the built environment. J. Econ. Geogr. 2015, 15, 815-839. [CrossRef]

51. Rode, J.; Müller, S. I Spot, I Adopt! Peer Effects and Visibility in Solar Photovoltaic System Adoption of Households, SSRN 2020. [CrossRef]

52. Selvakkumaran, S.; Ahlgren, E. Model-Based Exploration of Co-Creation Efforts: The Case of Solar Photovoltaics (PV) in Skåne, Sweden. Sustainability 2018, 10, 3905. [CrossRef] 
53. Sommerfeld, J.; Buys, L.; Vine, D. Residential consumers' experiences in the adoption and use of solar PV. Energy Policy 2017, 105, 10-16. [CrossRef]

54. Fabrizio, K.R.; Hawn, O. Enabling diffusion: How complementary inputs moderate the response to environmental policy. Res. Policy 2013, 42, 1099-1111. [CrossRef]

55. Karakaya, E.; Hidalgo, A.; Nuur, C. Motivators for adoption of photovoltaic systems at grid parity: A case study from Southern Germany. Renew. Sustain. Energy Rev. 2015, 43, 1090-1098. [CrossRef]

56. Zedan, S.; Miller, W. Quantifying stakeholders' influence on energy efficiency of housing: development and application of a four-step methodology. Constr. Manag. Econ. 2018, 36, 375-393. [CrossRef]

57. Michelsen, C.C.; Madlener, R. Homeowners' preferences for adopting innovative residential heating systems: A discrete choice analysis for Germany. Energy Econ. 2012, 34, 1271-1283. [CrossRef]

58. Noll, D.; Dawes, C.; Rai, V. Solar Community Organizations and active peer effects in the adoption of residential PV. Energy Policy 2014, 67, 330-343. [CrossRef]

59. Frantzeskaki, N.; Dumitru, A.; Anguelovski, I.; Avelino, F.; Bach, M.; Best, B.; Binder, C.; Barnes, J.; Carrus, G.; Egermann, M.; et al. Elucidating the changing roles of civil society in urban sustainability transitions. Curr. Opin. Environ. Sustain. 2016, 22, 41-50. [CrossRef]

60. Jager, W. Stimulating the diffusion of photovoltaic systems: A behavioural perspective. Energy Policy 2006, 34, 1935-1943. [CrossRef]

61. Kwan, C.L. Influence of local environmental, social, economic and political variables on the spatial distribution of residential solar PV arrays across the United States. Energy Policy 2012, 47, 332-344. [CrossRef]

62. de Groote, O.; Pepermans, G.; Verboven, F. Heterogeneity in the adoption of photovoltaic systems in Flanders. Energy Econ. 2016, 59, 45-57. [CrossRef]

63. Beise, M.; Rennings, K. Lead markets and regulation: A framework for analyzing the international diffusion of environmental innovations. Ecol. Econ. 2005, 52, 5-17. [CrossRef]

64. Wüstenhagen, R.; Bilharz, M. Green energy market development in Germany: Effective public policy and emerging customer demand. Energy Policy 2006, 34, 1681-1696. [CrossRef]

65. Davies, P.; Osmani, M. Low carbon housing refurbishment challenges and incentives: Architects' perspectives. Build. Environ. 2011, 46, 1691-1698. [CrossRef]

66. Parag, Y.; Janda, K.B. More than filler: Middle actors and socio-technical change in the energy system from the "middle-out". Energy Res. Soc. Sci. 2014, 3, 102-112. [CrossRef]

67. Reeves, D.C.; Rai, V.; Margolis, R. Evolution of consumer information preferences with market maturity in solar PV adoption. Environ. Res. Lett. 2017, 12, 074011. [CrossRef]

68. Southwell, B.G.; Murphy, J.J.; DeWaters, J.E.; LeBaron, P.A.; Willoughby, J.F. Energy information sharing in social networks: The roles of objective knowledge and perceived understanding. J. Sustain. Educ. 2014, 2014, 1-7.

69. Freeman, R.E. Strategic Management: A Stakeholder Approach; Pitsman: Boston, MA, USA, 1984.

70. Nelson, D.; Quick, J. Organizational Behavior: Foundations, Realities and Challenges; West Publishing Company: St. Paul, MN, USA, 1994.

71. French, J.; Raven, B. The bases of social power in Cartwright. In Studies in Social Power; Univer. Michigan: Ann Arbor, MI, USA, 1959; pp. 150-167.

72. Raven, B.H. The bases of power and the power/interaction model of interpersonal influence. Anal. Soc. Issues Public Policy 2008, 8, 1-22. [CrossRef]

73. Ohanian, R. Construction and validation of a scale to measure celebrity endorsers' perceived expertise, trustworthiness, and attractiveness. J. Advert. 1990, 19, 39-52. [CrossRef]

74. Lui, L.; Standing, L. Communicator credibility: Trustworthiness defeats expertness. Soc. Behav. Personal. Int. J. 1989, 17. [CrossRef]

75. DeSarbo, W.S.; Harshman, R.A. Celebrity-brand congruence analysis. Curr. Issues Res. Advert. 1985, 8, 17-52. [CrossRef]

76. Steiner, I.E.; Fishbein, M.E. Current Studies in Social Psychology; Holt, Rinehart and Winston: New York, NY, USA, 1965. 
77. Hägerstrand, T. A Monte Carlo approach to diffusion. Eur. J. Sociol. Eur. Sociol. Arch. Soziologie 1965, 6, $43-67$. [CrossRef]

78. Meyners, J.; Barrot, C.; Becker, J.U.; Goldenberg, J. The role of mere closeness: How geographic proximity affects social influence. J. Mark. 2017, 81, 49-66. [CrossRef]

79. Kosugi, T.; Shimoda, Y.; Tashiro, T. Neighborhood influences on the diffusion of residential photovoltaic systems in Kyoto City, Japan. Environ. Econ. Policy Stud. 2019, 21, 477-505. [CrossRef]

80. Müller, S.; Rode, J. The adoption of photovoltaic systems in Wiesbaden, Germany. Econ. Innov. New Technol. 2013, 22, 519-535. [CrossRef]

81. Rode, J.; Weber, A. Does localized imitation drive technology adoption? A case study on rooftop photovoltaic systems in Germany. J. Environ. Econ. Manag. 2016, 78, 38-48. [CrossRef]

82. Sloot, D.; Jans, L.; Steg, L. Can community energy initiatives motivate sustainable energy behaviours? The role of initiative involvement and personal pro-environmental motivation. J. Environ. Psychol. 2018, 57, 99-106. [CrossRef]

83. Parag, Y.; Hamilton, J.; White, V.; Hogan, B. Network approach for local and community governance of energy: The case of Oxfordshire. Energy Policy 2013, 62, 1064-1077. [CrossRef]

84. Scheller, F.; Burkhardt, R.; Schwarzeit, R.; McKenna, R.; Bruckner, T. Competition between simultaneous demand-side flexibility options: The case of community electricity storage systems. Appl. Energy 2020, $269,114969$. [CrossRef]

85. McKenna, R. The double-edged sword of decentralized energy autonomy. Energy Policy 2018, 113, 747-750. [CrossRef]

86. Scheller, F.; Johanning, S.; Seim, S.; Schuchardt, K.; Krone, J.; Haberland, R.; Bruckner, T. Legal Framework of Decentralized Energy Business Models in Germany: Challenges and Opportunities for Municipal Utilities. Z. Energiewirtschaft 2018, 42, 207-223. [CrossRef]

87. Richter, M. Utilities' business models for renewable energy: A review. Renew. Sustain. Energy Rev. 2012, 16, 2483-2493. [CrossRef]

88. Weniger, J.; Tjaden, T.; Quaschning, V. PV-Eigenverbrauch: Ökonomie von Photovoltaiksystemen im Eigenverbrauchszeitalter. Sonnenenergie 2014, April-Mai, 26-27.

89. Zhang, H.; Vorobeychik, Y.; Letchford, J.; Lakkaraju, K. Data-driven agent-based modeling, with application to rooftop solar adoption. Auton. Agents Multi-Agent Syst. 2016, 30, 1023-1049. [CrossRef]

90. Ragwitz, M.; Held, A.; Resch, G.; Faber, T.; Huber, C.; Haas, R. Monitoring and Evaluation of policy Instruments to Support Renewable Electricity in EU Member States; Umweltbundesamt: Dessau-Roßlau, Germany, 2006.

91. Shum, K.L. A general technology adoption model of solar photovoltaic under feed-in tariff policy incorporating learning and network effects. J. Renew. Sustain. Energy 2013, 5, 043128. [CrossRef]

92. Held, A. Assessing the Performance of Renewable Energy Support Policies with Quantitative Indicators-Update 2014; European project DIACORE: Brussels, Belgium, 2015.

93. Dusonchet, L.; Telaretti, E. Comparative economic analysis of support policies for solar PV in the most representative EU countries. Renew. Sustain. Energy Rev. 2015, 42, 986-998. [CrossRef]

94. Ragwitz, M.; Steinhilber, S. Effectiveness and efficiency of support schemes for electricity from renewable energy sources. Wiley Interdiscip. Rev. Energy Environ. 2014, 3, 213-229. [CrossRef]

95. Rutschmann, I. Zuschüsse und günstige Kredite für Solaranlage und Batteriespeicher. Available online: https: / / www.finanztip.de/photovoltaik/pv-foerderung/ (accessed on 01 November 2020).

96. KfW. Erneuerbare Energien-Standard: Der Förderkredit für Strom und Wärme. Available online: https:/ / www.kfw.de/inlandsfoerderung/Privatpersonen/Bestandsimmobilie/F\%C3\%B6rderprodukte/ Eneuerbare-Energien-Standard-(270)/ (accessed on 01 November 2020).

97. Wollmann, H. Local Government Reforms in Great Britain, Sweden, Germany and France: Between Multi-Function and Single-Purpose Organisations. Local Gov. Stud. 2004, 30, 639-665. [CrossRef] 
98. Kern, K.; Niederhafner, S.; Rechlin, S.; Wagner, J. Kommunaler Klimaschutz in Deutschland-Handlungsoptionen, Entwicklung und Perspektiven. In Discussion Papers/Wissenschaftszentrum Berlin fur Sozialforschung; Wissenschaftszentrum Berlin fur Sozialforschung gGmbH: Berlin, Germany, 2005; Volume 2005-101, p. 117.

99. Korcaj, L.; Hahnel, U.J.; Spada, H. Intentions to adopt photovoltaic systems depend on homeowners' expected personal gains and behavior of peers. Renew. Energy 2015, 75, 407-415. [CrossRef]

100. Dóci, G.; Vasileiadou, E. “Let's do it ourselves” Individual motivations for investing renewables at community level. Renew. Sustain. Energy Rev. 2014, 49, 1-25. [CrossRef]

101. Schelly, C. Residential solar electricity adoption: What motivates, and what matters? A case study of early adopters. Energy Res. Soc. Sci. 2014, 2, 183-191. [CrossRef]

102. Sovacool, B.K.; Axsen, J.; Sorrell, S. Promoting Novelty, Rigor, and Style in Energy Social Science: Towards Codes of Practice for Appropriate Methods and Research Design; Energy Res. Soc. Sci. 2018, 45, 12-42. [CrossRef]

103. Davis, A.L.; Krishnamurti, T.; Fischhoff, B.; Bruine de Bruin, W. Setting a standard for electricity pilot studies. Energy Policy 2013, 62, 401-409. [CrossRef]

104. Frederiks, E.R.; Stenner, K.; Hobman, E.V.; Fischle, M. Evaluating energy behavior change programs using randomized controlled trials: Best practice guidelines for policymakers. Energy Res. Soc. Sci. 2016, 22, 147-164. [CrossRef]

105. Johanning, S.; Scheller, F.; Abitz, D.; Wehner, C.; Bruckner, T. A modular multi-agent framework for innovation diffusion in changing business environments: Conceptualization, formalization and implementation. Complex Adapt. Syst. Model. 2020, 8, 1-32. [CrossRef]

Publisher's Note: MDPI stays neutral with regard to jurisdictional claims in published maps and institutional affiliations.

(C) 2020 by the authors. Licensee MDPI, Basel, Switzerland. This article is an open access article distributed under the terms and conditions of the Creative Commons Attribution (CC BY) license (http://creativecommons.org/licenses/by/4.0/). 